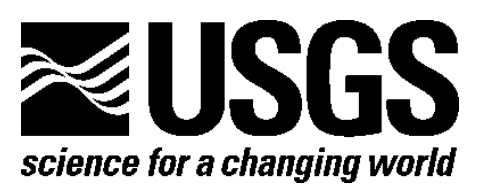

\title{
Predicted Surface Displacements for Scenario Earthquakes in the San Francisco Bay Region
}

By Jessica R. Murray-Moraleda

Open-File Report 2008-1375

U.S. Department of the Interior

U.S. Geological Survey 


\section{U.S. Department of the Interior \\ DIRK KEMPTHORNE, Secretary}

\section{U.S. Geological Survey \\ Mark D. Myers, Director}

U.S. Geological Survey, Reston, Virginia 2008

For product and ordering information:

World Wide Web: http://www.usgs.gov/pubprod

Telephone: 1-888-ASK-USGS

For more information on the USGS-the Federal source for science about the Earth,

its natural and living resources, natural hazards, and the environment:

World Wide Web: http://www.usgs.gov

Telephone: 1-888-ASK-USGS

Suggested citation:

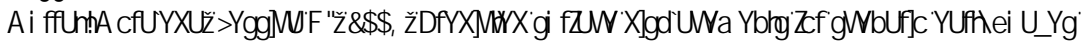

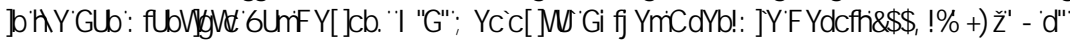

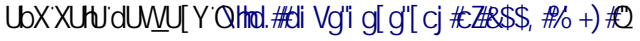

Any use of trade, product, or firm names is for descriptive purposes only and does not imply endorsement by the U.S. Government.

Although this report is in the public domain, permission must be secured from the individual copyright owners to reproduce any copyrighted material contained within this report. 


\section{Contents}

Introduction

Method .

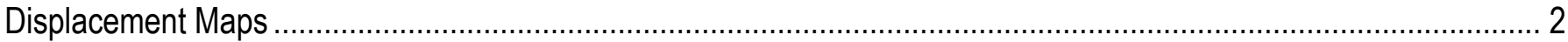

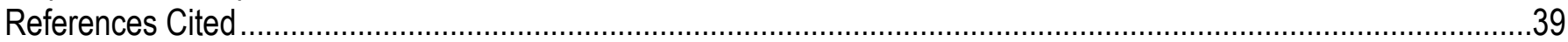

\section{Figures}

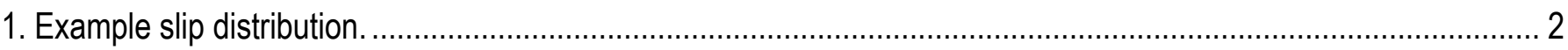

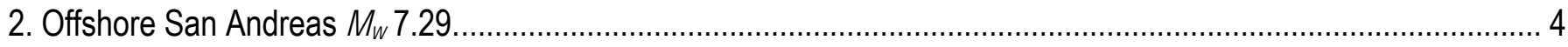

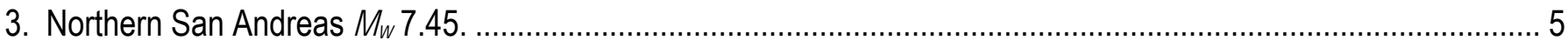

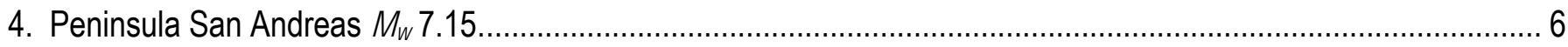

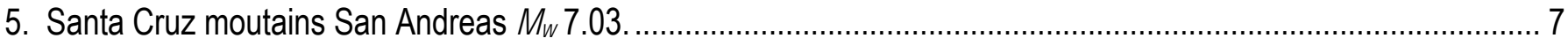

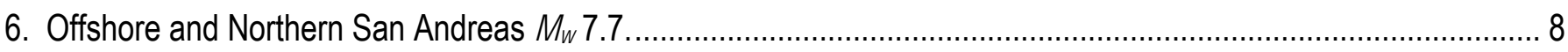

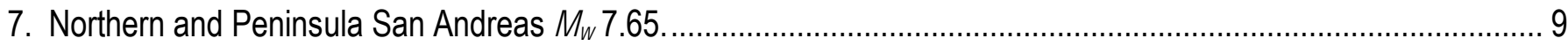

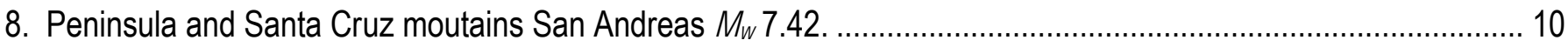

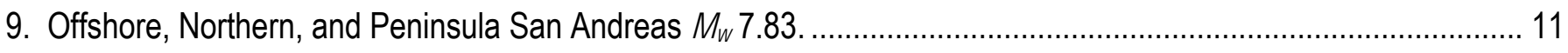

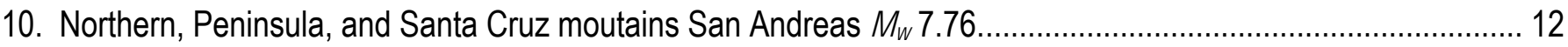

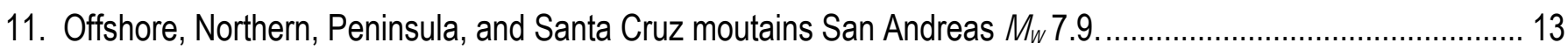

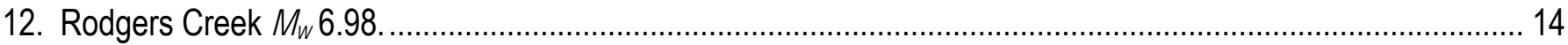

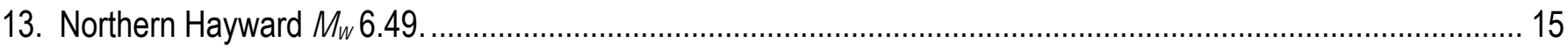

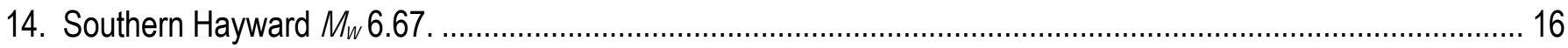

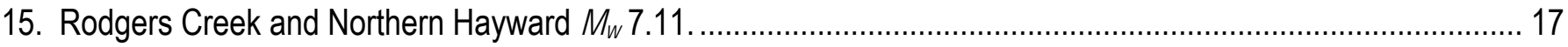

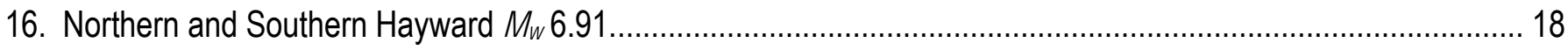

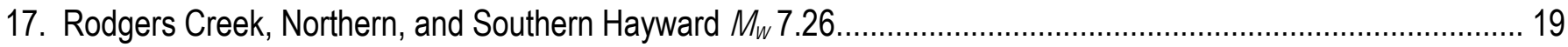

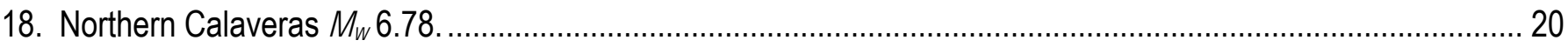

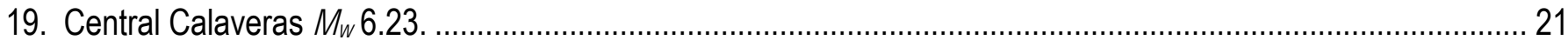




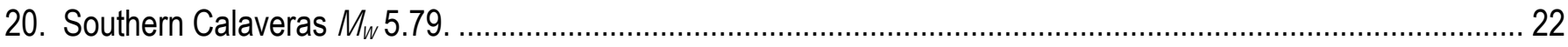

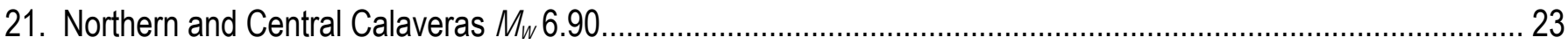

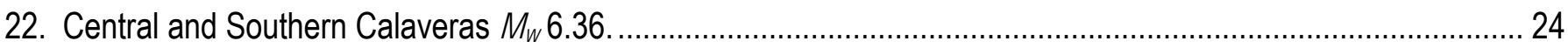

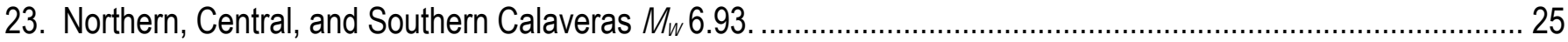

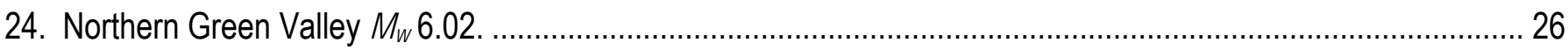

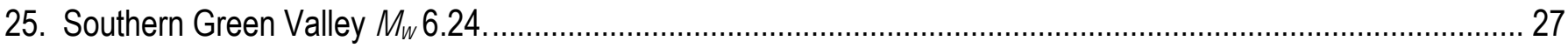

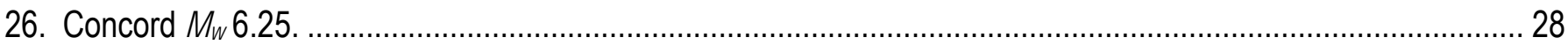

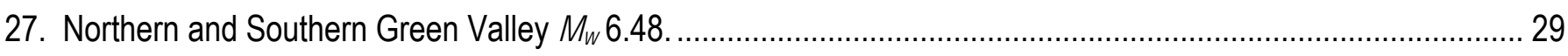

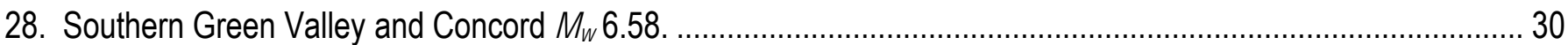

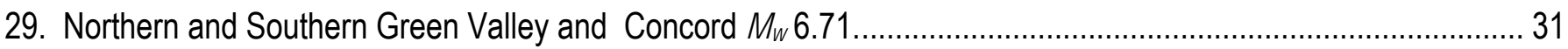

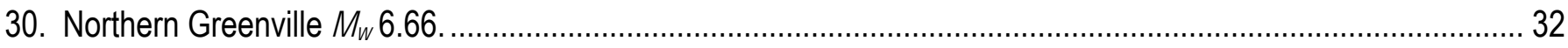

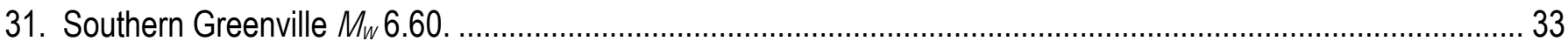

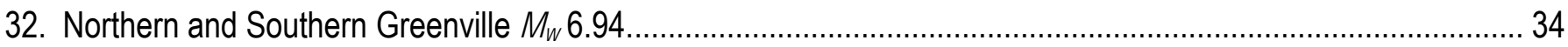

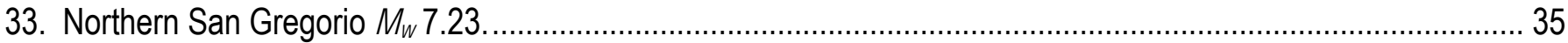

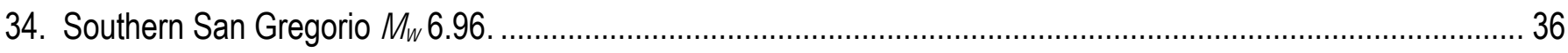

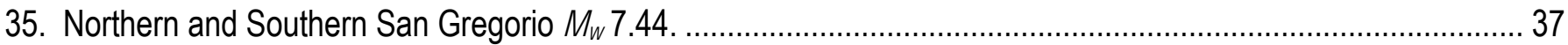

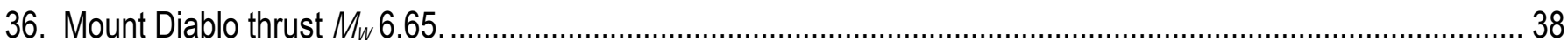




\section{Conversion Factors}

Inch/Pound to SI

\begin{tabular}{lcl}
\hline & Multiply & \multicolumn{1}{c}{ By obtain } \\
\hline & Length & \\
\hline inch (in.) & 2.54 & centimeter (cm) \\
inch (in.) & 25.4 & millimeter (mm) \\
foot (ft) & 0.3048 & meter (m) \\
mile (mi) & 1.609 & kilometer (km) \\
yard (yd) & 0.9144 & meter (m) \\
\hline & Force & \\
\hline dyne (dyn) & $10^{-5}$ & Newton (N)
\end{tabular}




\title{
Predicted Surface Displacements for Scenario Earthquakes in the San Francisco Bay Area
}

\author{
By Jessica R. Murray-Moraleda
}

\section{Introduction}

In the immediate aftermath of a major earthquake, the U.S. Geological Survey (USGS) will be called upon to provide information on the characteristics of the event to emergency responders and the media. One such piece of information is the expected surface displacement due to the earthquake. In conducting probabilistic hazard analyses for the San Francisco Bay Region, the Working Group on California Earthquake Probabilities (WGCEP) identified a series of scenario earthquakes involving the major faults of the region, and these were used in their 2003 report (hereafter referred to as WG03) and the recently released 2008 Uniform California Earthquake Rupture Forecast (UCERF). Here I present a collection of maps depicting the expected surface displacement resulting from those scenario earthquakes.

The USGS has conducted frequent Global Positioning System (GPS) surveys throughout northern California for nearly two decades, generating a solid baseline of interseismic measurements. Following an earthquake, temporary GPS deployments at these sites will be important to augment the spatial coverage provided by continuous GPS sites for recording postseismic deformation, as will the acquisition of Interferometric Synthetic Aperture Radar (InSAR) scenes. The information provided in this report allows one to anticipate, for a given event, where the largest displacements are likely to occur. This information is valuable both for assessing the need for further spatial densification of GPS coverage before an event and prioritizing sites to resurvey and InSAR data to acquire in the immediate aftermath of the earthquake. In addition, these maps are envisioned to be a resource for scientists in communicating with emergency responders and members of the press, particularly during the time immediately after a major earthquake before displacements recorded by continuous GPS stations are available.

\section{Method}

The source geometries for the scenario earthquakes are those in the California Reference Geologic Fault Parameter Database

(http://gravity.usc.edu/WGCEP/resources/data/refFaultParams/index.html, last accessed February 11, 2009) compiled by the USGS, California Geological Survey, and the Southern California Earthquake Center and used in the 2008 Uniform California Earthquake Rupture Forecast (UCERF) report produced by the 2007 WGCEP. These source geometries are provided as an input file with the Coulomb 3 software (Lin and Stein, 2004; Toda and others, 2005), and this software (version 3.1.09, May 2008) was used to calculate and plot the surface displacements.

To produce the displacement maps I first developed a slip distribution for each scenario earthquake as follows. The magnitude assigned to the scenario by WG03 was used to calculate the 
moment using equation 9.156 of Sleep and Fujita, 1997, $M_{w}=\left(\log M_{o}+7\right) / 1.5-10.7$, where $M_{w}$ is the moment magnitude and $\mathrm{M}_{\mathrm{o}}$ is the moment in Newton meters.

The slip was assumed to taper toward the edges of the fault rupture using three slip values in the ratio 0.1:0.5:1.0, as shown in figure 1 . The smaller dimension of each part of the fault with an intermediate or lower slip value is approximately $1 \mathrm{~km}$. For a given scenario earthquake, these initial slip magnitudes were multiplied by a scalar in order to produce the moment obtained from the magnitude. Using the fault geometries discussed above and these slip values, I then created Coulomb 3 input files for each scenario event. These input files are provided in ASCII form in a supplement to this report to enable others to generate more detailed plots or to modify source parameters (for instance to allow for greater near-surface slip). Finally, Coulomb 3 was used to calculate the predicted displacements for each scenario and to generate plots. These calculations assume a homogeneous elastic half space with a Poisson's ratio of 0.25 and use the expressions of Okada (1985).

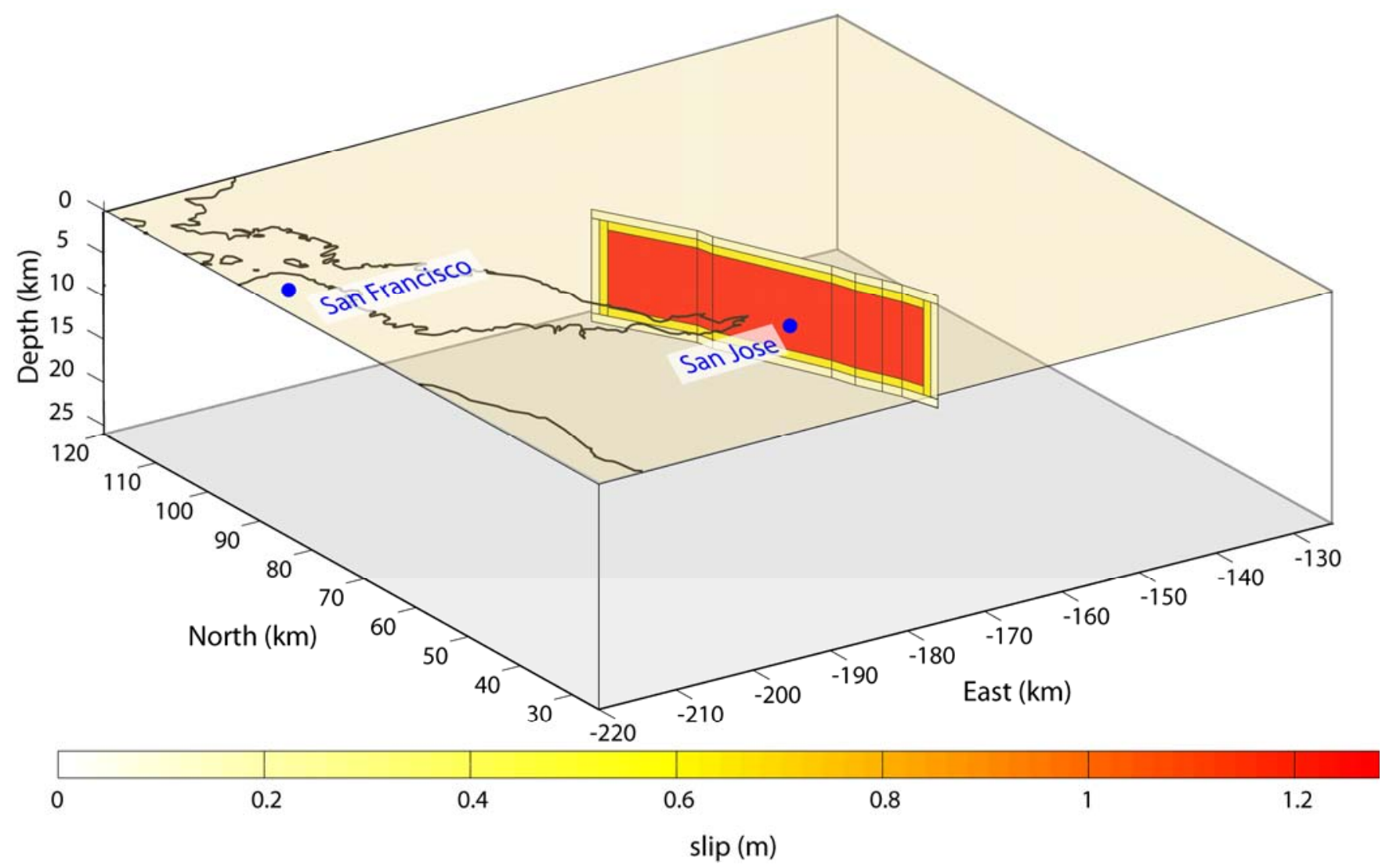

Figure 1. Example slip distribution for the Northern Calaveras M6.78 scenario earthquake. The slip increases from $0.1282 \mathrm{~m}$ at the edges to $0.6412 \mathrm{~m}$ and then to $1.282 \mathrm{~m}$ in the center, giving a moment of $1.661019 \mathrm{~N} \mathrm{~m}$.

\section{Displacement Maps}

Figures 2 through 36 show the predicted displacements for scenario events. To provide displacement information throughout the geographic region of interest, the displacements were calculated on a grid rather than at existing GPS site locations. Blue circles indicate the locations of existing continuous GPS sites for reference. Using the input files provided with this report, one can calculate displacements for any location. Horizontal displacements are given by vectors, and the 
background color shading shows vertical displacement. Contours of vertical displacement are shown in grey and coastlines in black. For vertical strike slip faults (all sources except the Mount Diablo thrust), the rupture is assumed to reach the Earth's surface, and the surface trace of the source fault is shown in green. In the case of the Mount Diablo thrust the vertical projection of the fault plane onto the Earth's surface is shown in white, and the up-dip projection of the upper edge is shown in green.

The predicted displacements presented here are a reasonable approximation to the displacements that would occur in a real event. However, assumptions made by this study (for example, the spatial distribution of slip and use of an elastic half-space approximation), as well as assumptions made in generating the scenario events (for example, fault geometry, rupture length, and magnitude), will no doubt give rise to differences between the predicted displacements and those observed following an actual earthquake, particularly for locations near the fault rupture. 


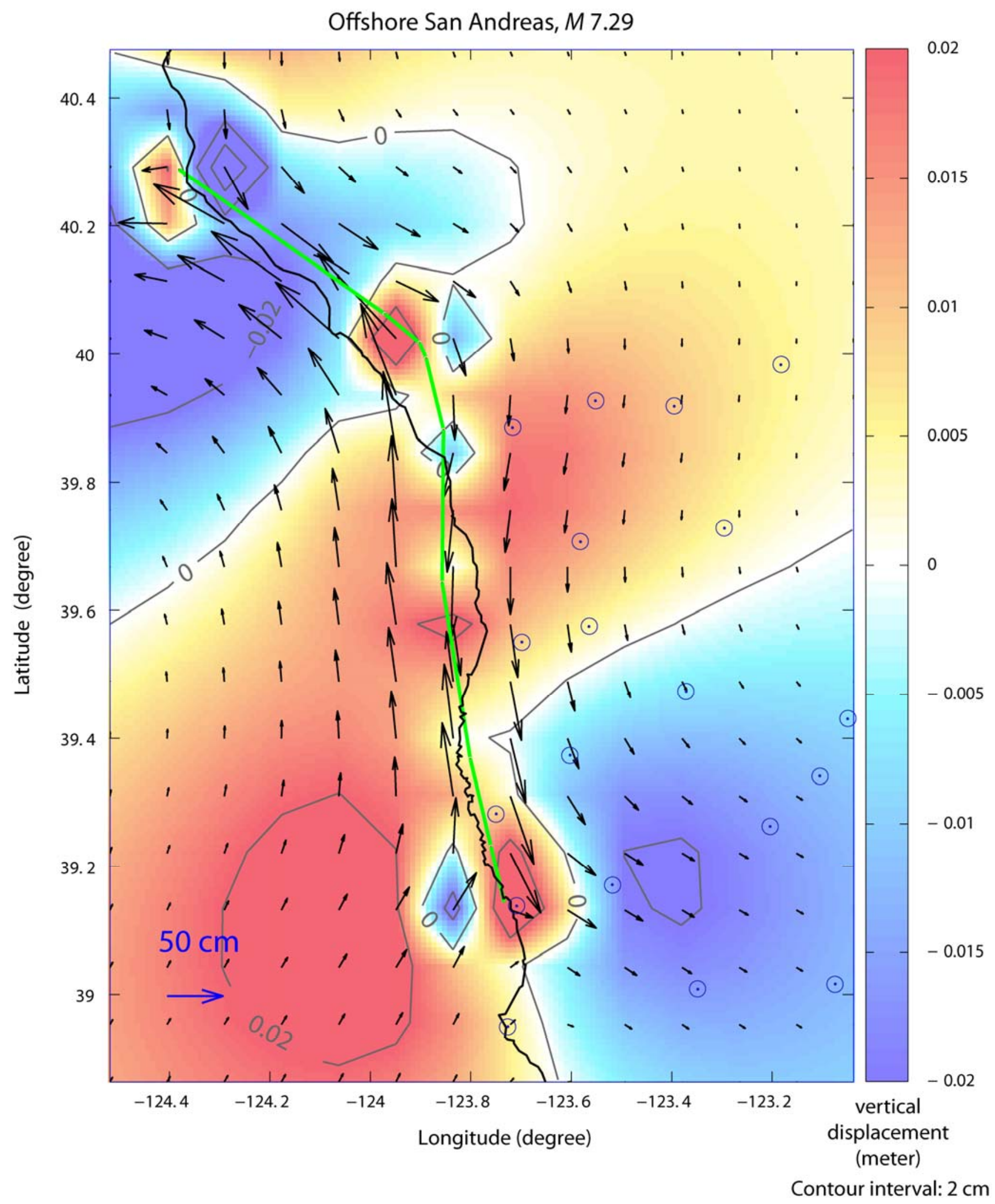

Figure 2. Predicted displacements for scenario offshore San Andreas fault earthquake. 


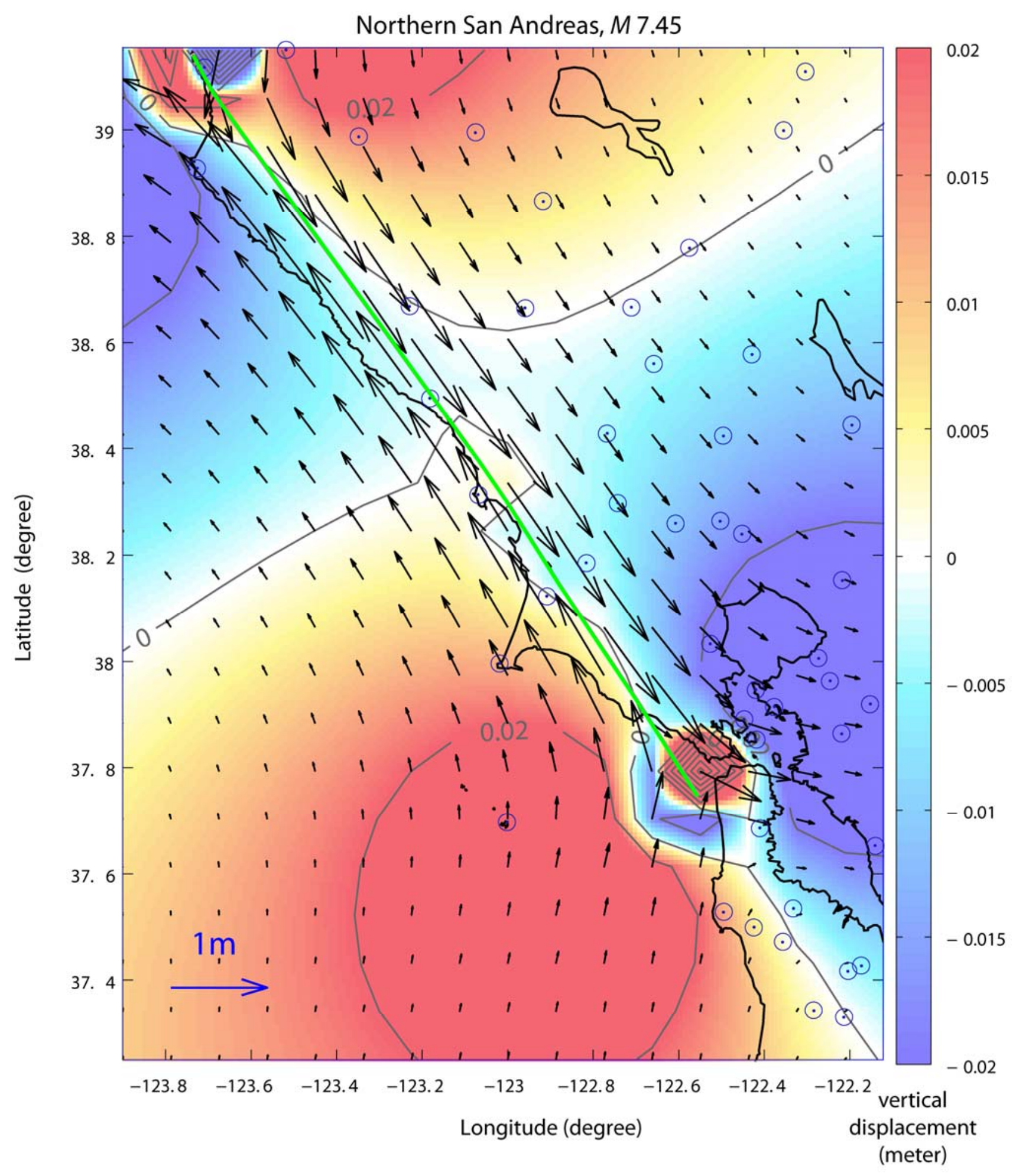

Contour interval: $2 \mathrm{~cm}$

Figure 3. Predicted displacements for scenario northern San Andreas fault earthquake. 


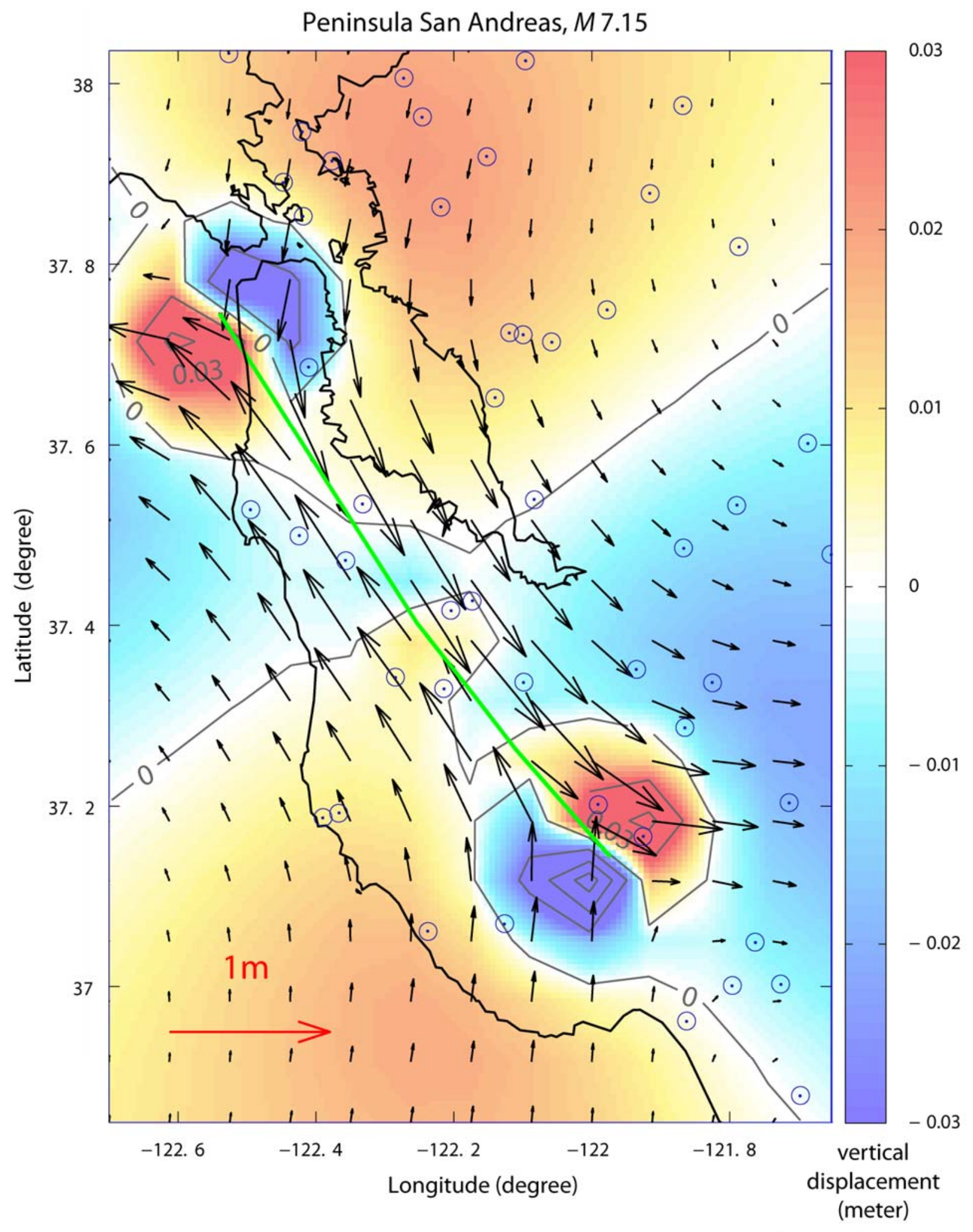

Contour interval: $3 \mathrm{~cm}$

Figure 4. Predicted displacements for scenario peninsula San Andreas fault earthquake. 


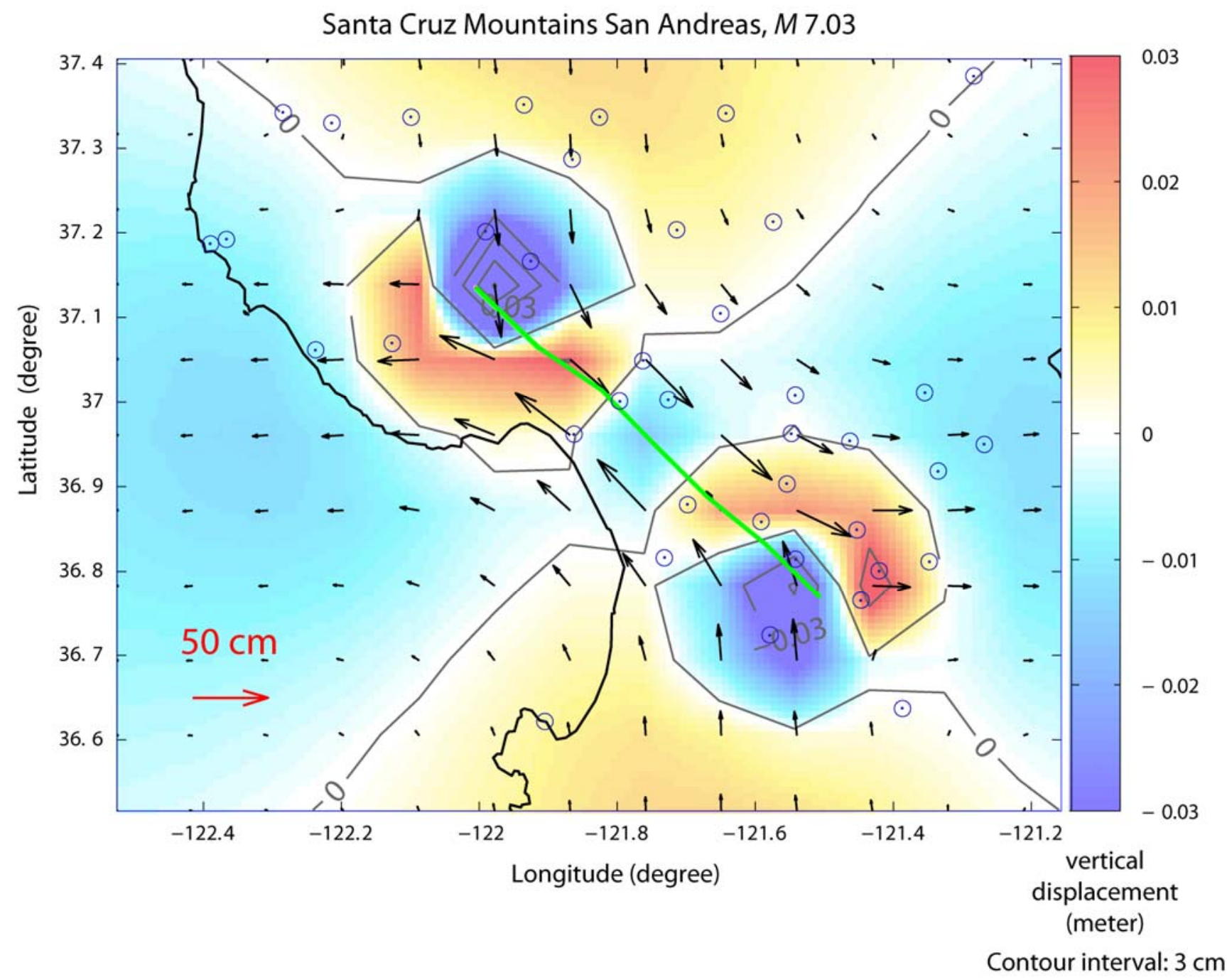

Figure 5. Predicted displacements for scenario Santa Cruz mountains San Andreas fault earthquake. 


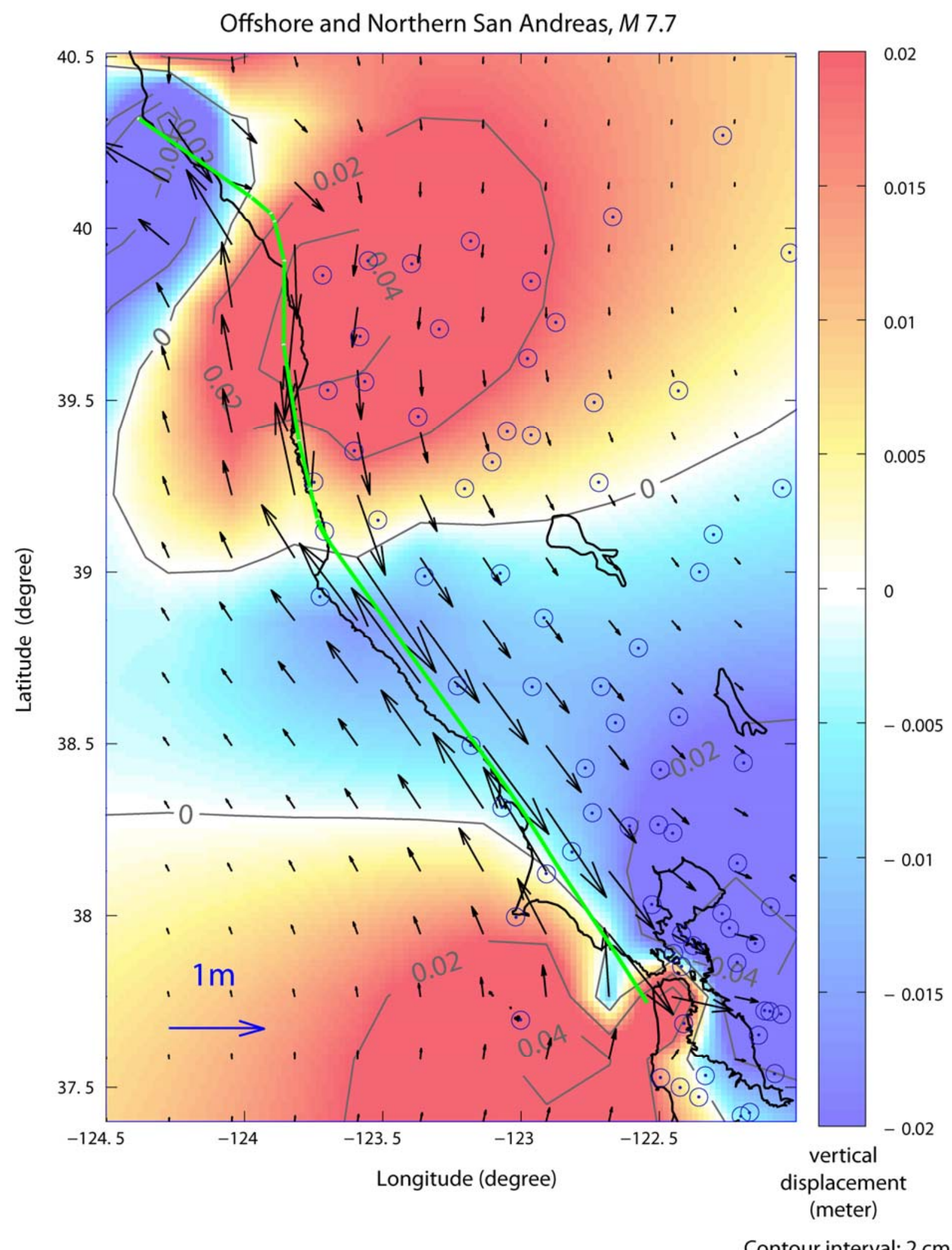

Figure 6. Predicted displacements for scenario offshore and northern San Andreas fault earthquake. 


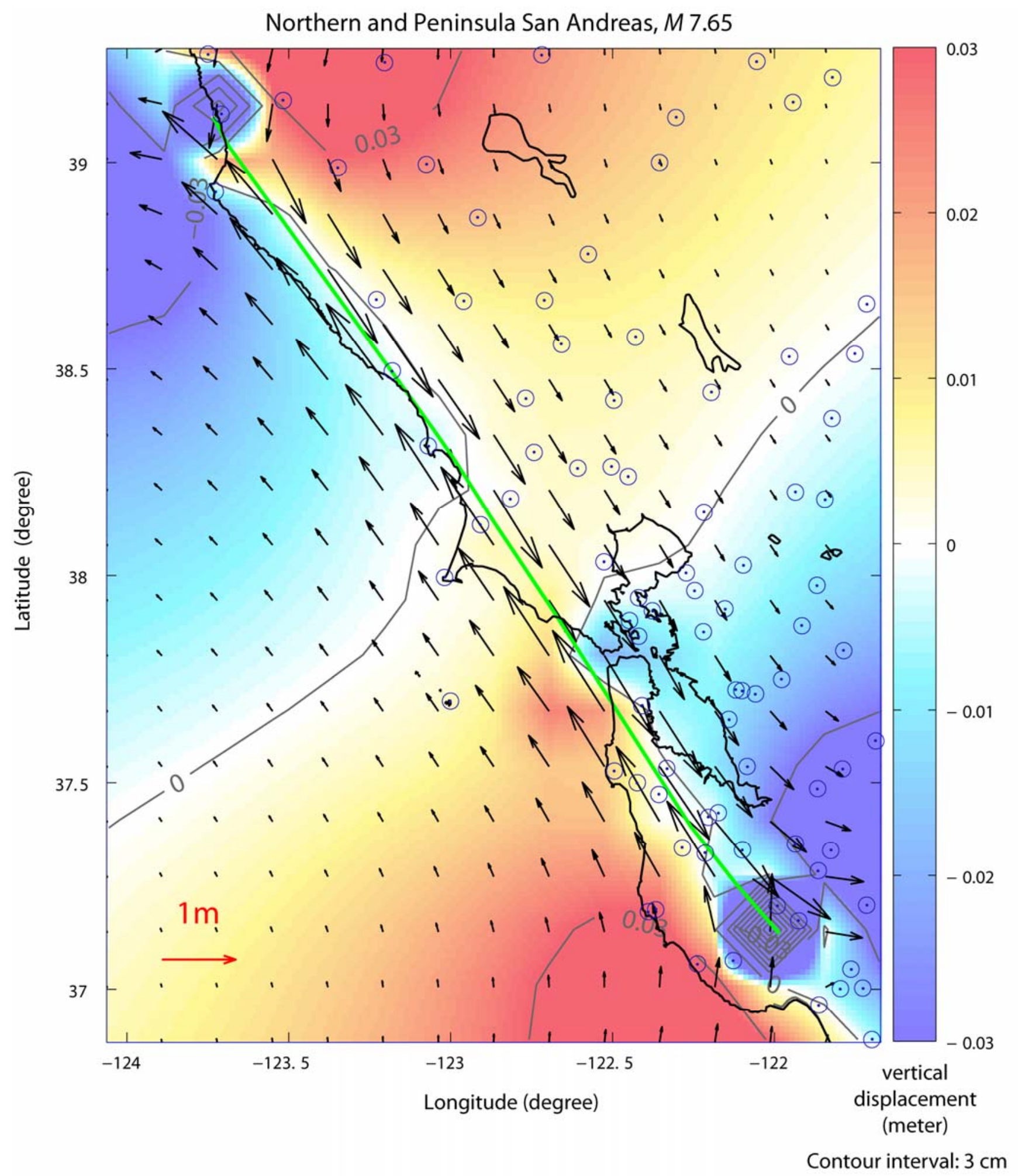

Figure 7. Predicted displacements for scenario northern and peninsula San Andreas fault earthquake. 


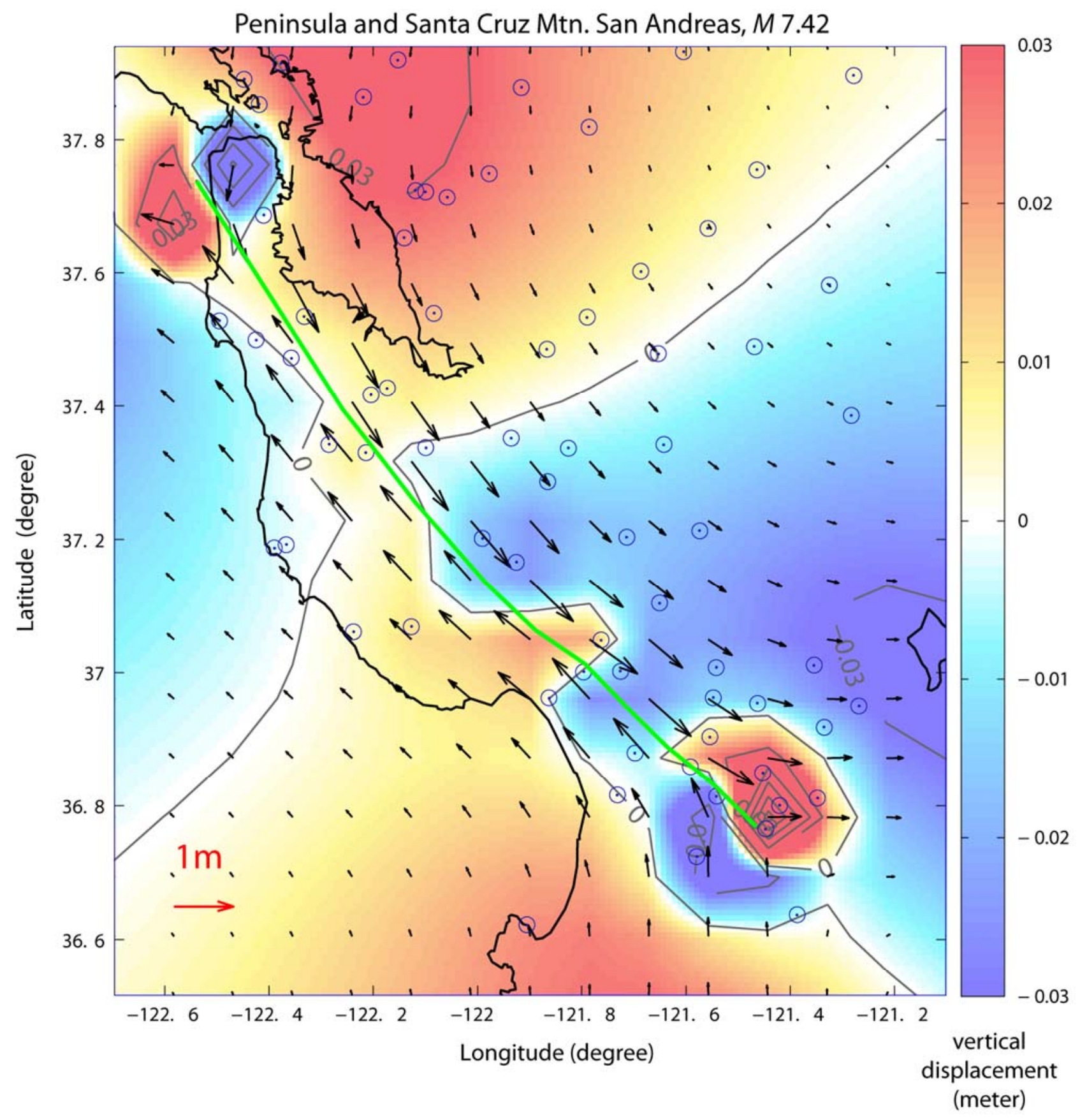

Contour interval: $3 \mathrm{~cm}$

Figure 8. Predicted displacements for scenario peninsula and Santa Cruz mountains San Andreas fault earthquake. 


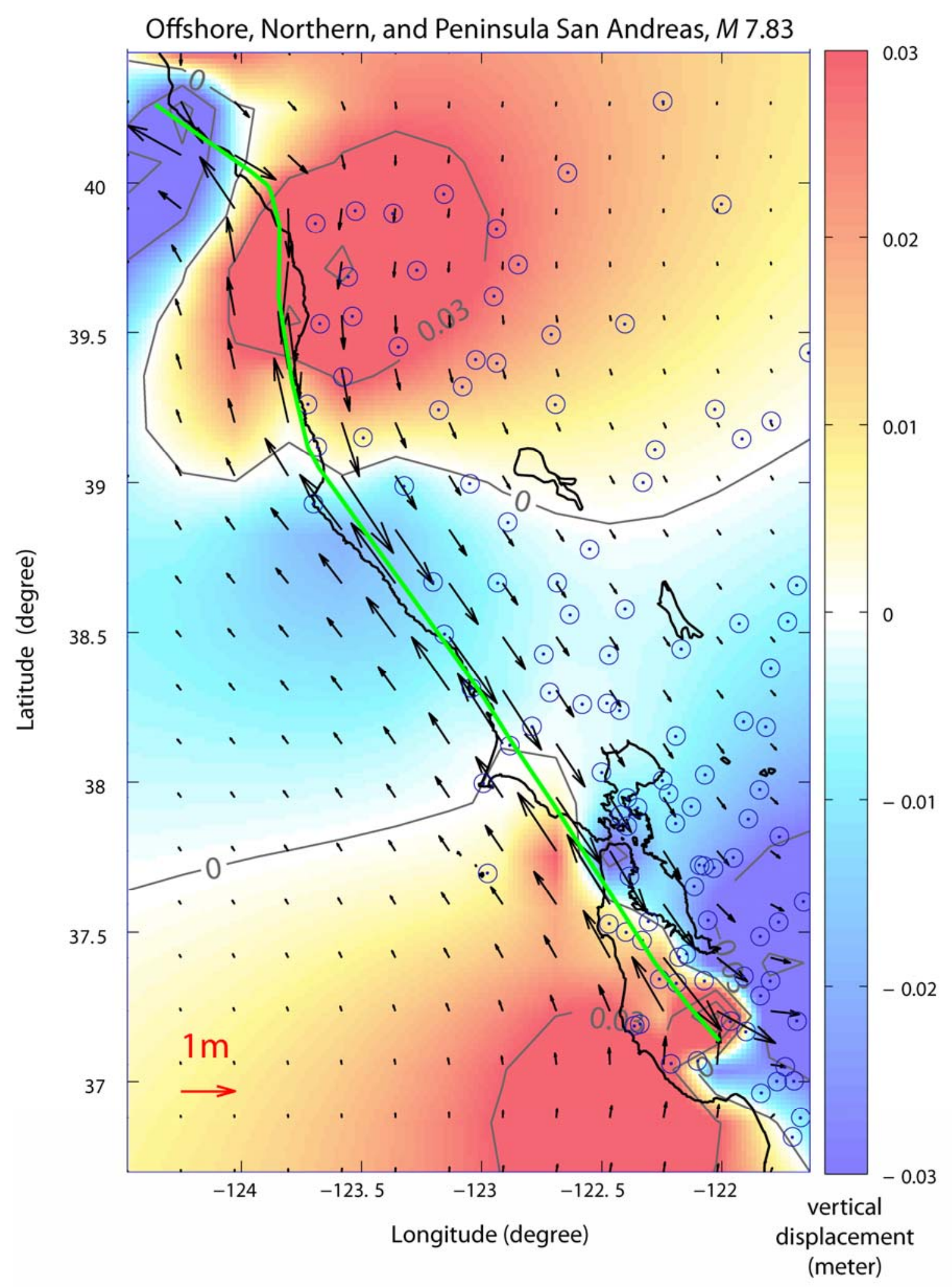

Contour interval: $3 \mathrm{~cm}$

Figure 9. Predicted displacements for scenario offshore, northern, and peninsula San Andreas fault earthquake. 


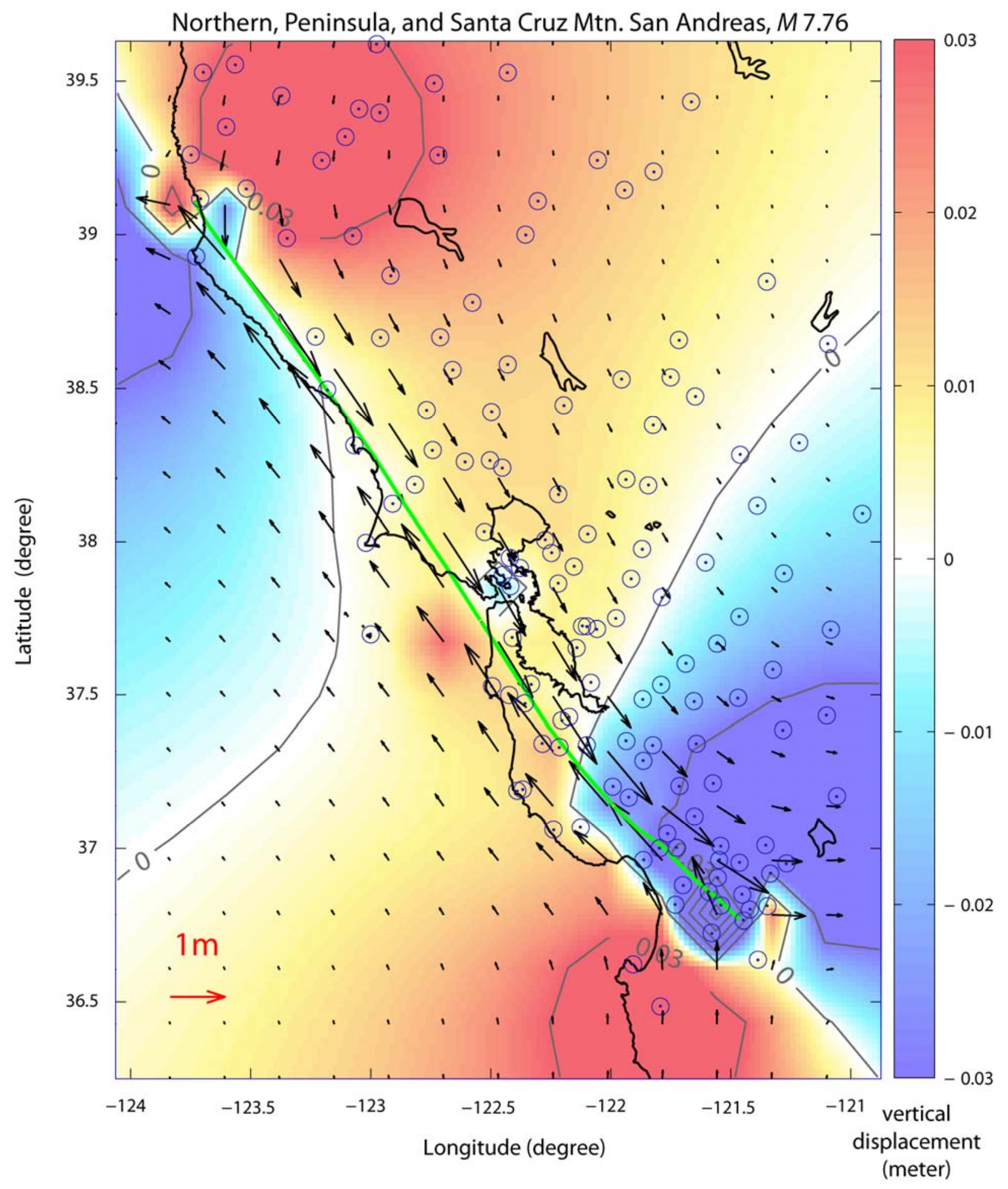

Contour interval: $3 \mathrm{~cm}$

Figure 10. Predicted displacements for scenario northern, peninsula, and Santa Cruz mountains San Andreas fault earthquake. 


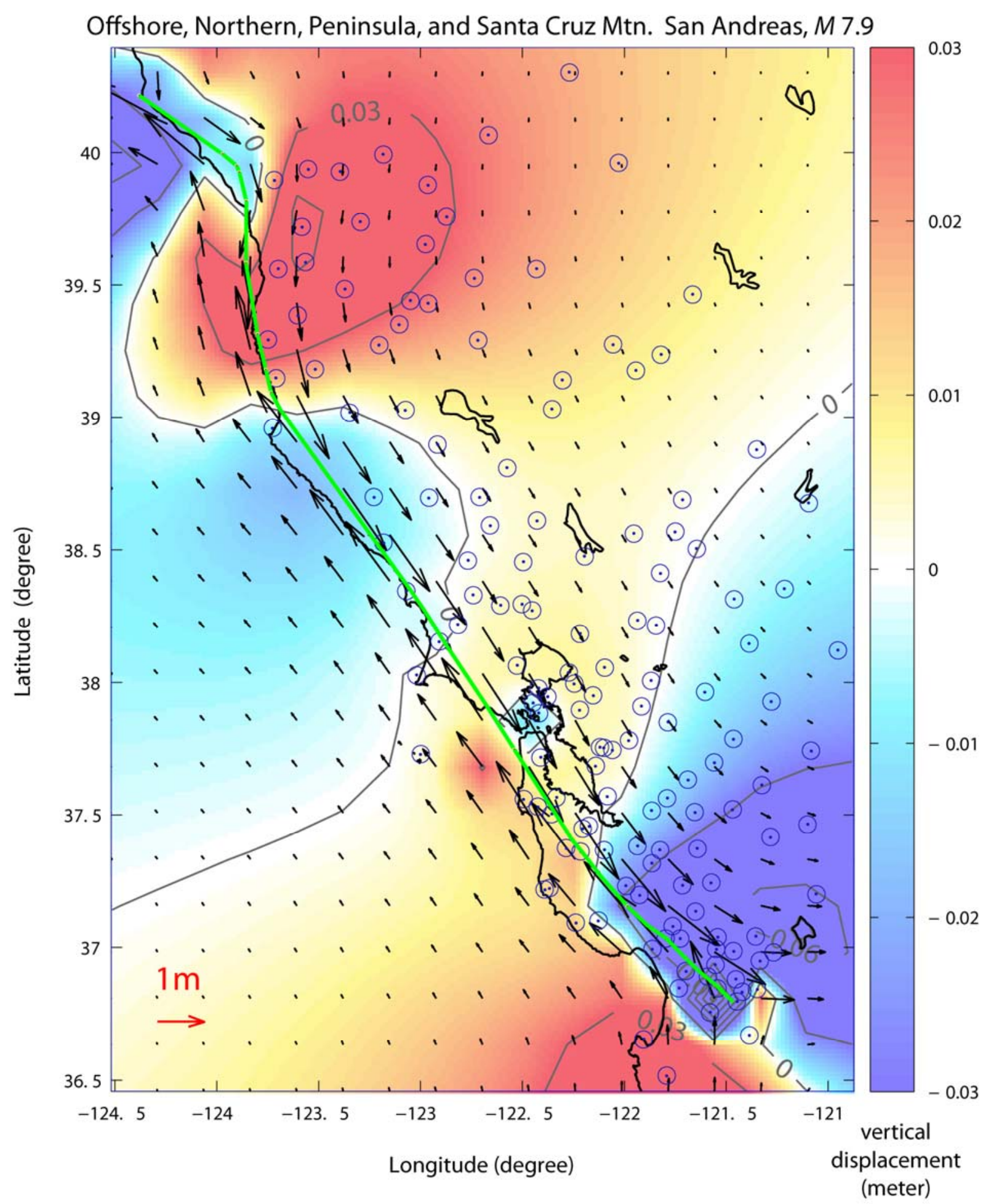

Contour interval: $3 \mathrm{~cm}$

Figure 11. Predicted displacements for scenario offshore, northern, peninsula, and Santa Cruz mountains San Andreas fault earthquake. 


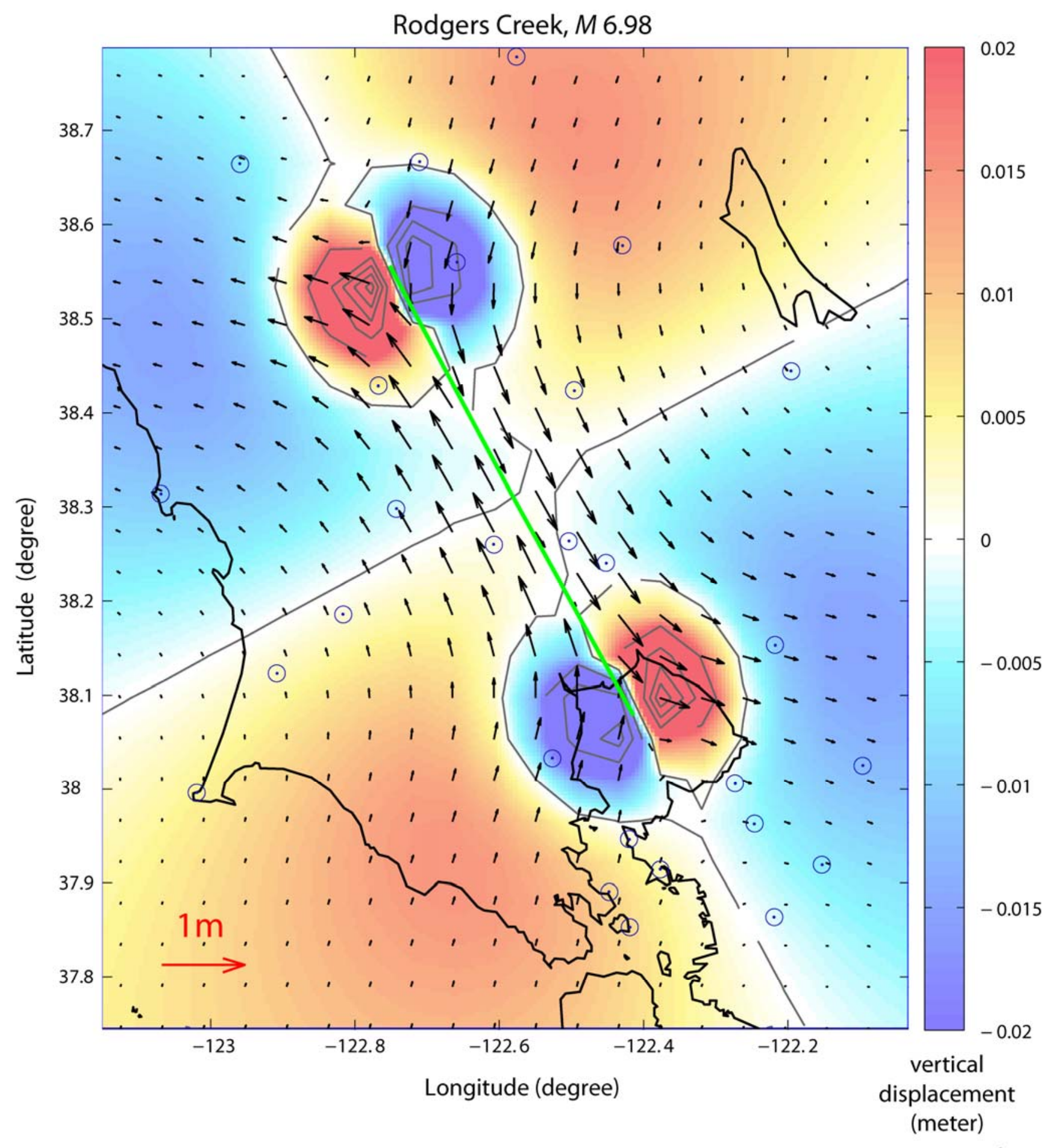

Contour interval: $2 \mathrm{~cm}$

Figure 12. Predicted displacements for scenario Rodgers Creek fault earthquake. 


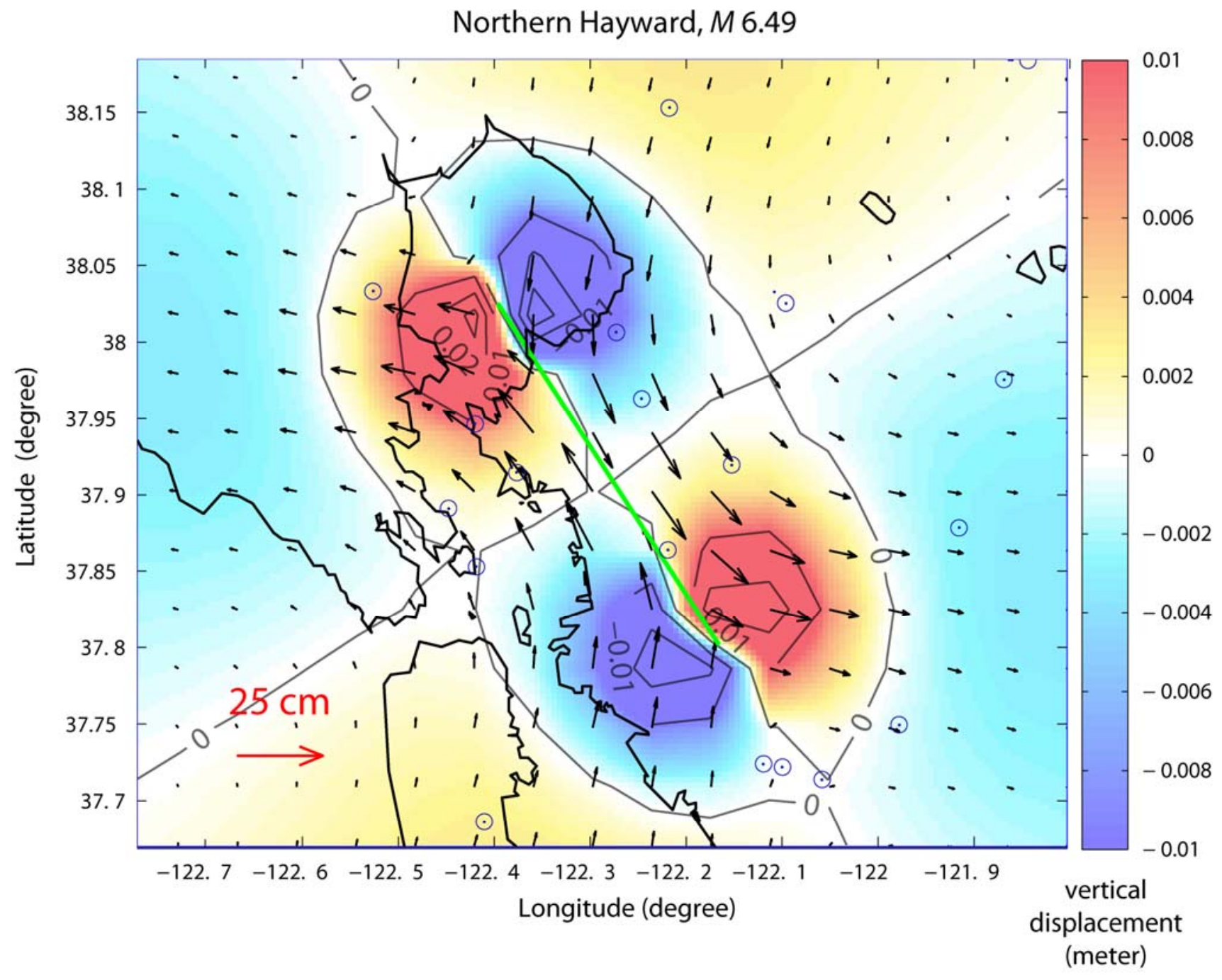

Contour interval: $1 \mathrm{~cm}$

Figure 13. Predicted displacements for scenario northern Hayward fault earthquake. 
Southern Hayward, M 6.67

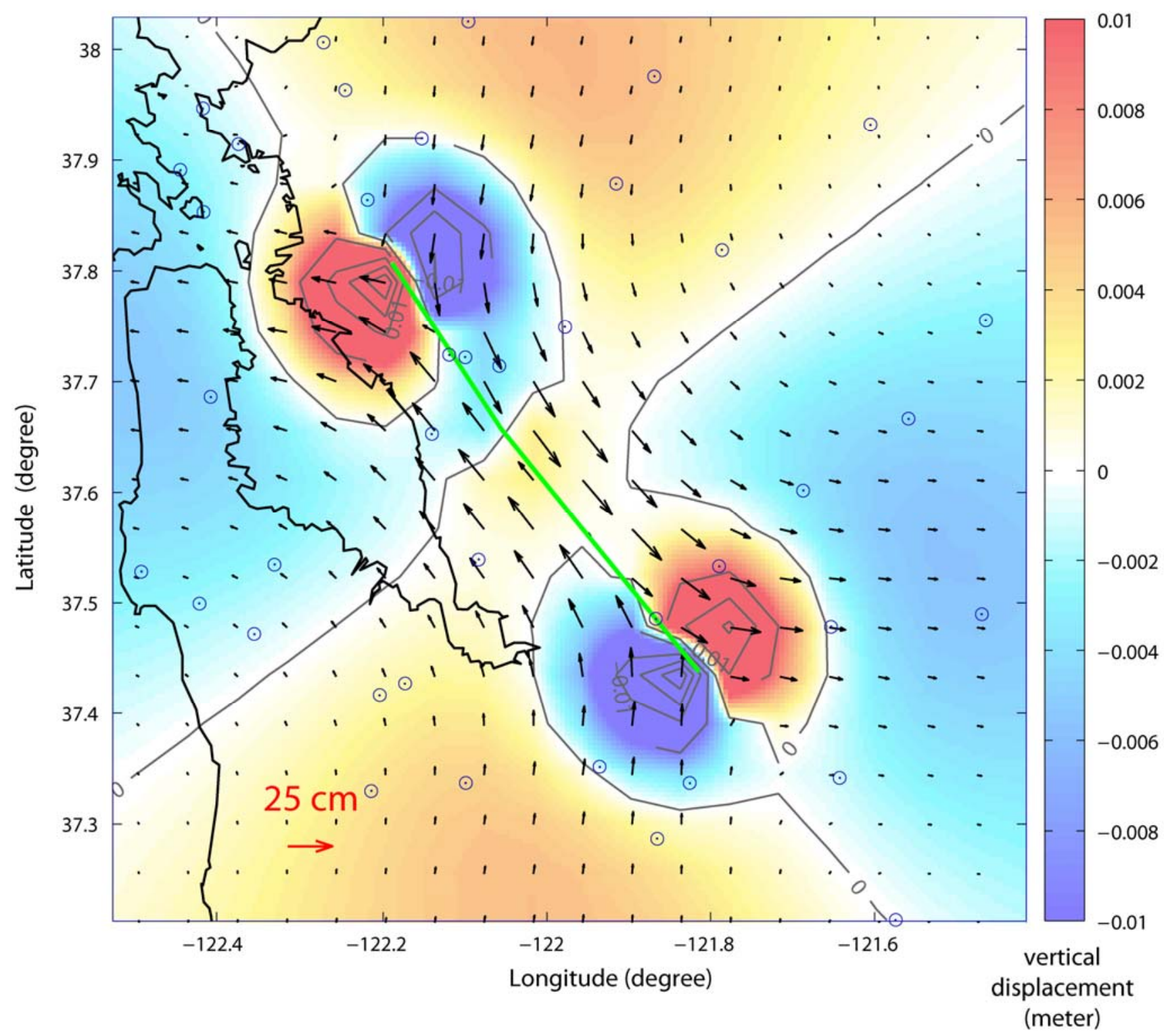

Contour interval: $1 \mathrm{~cm}$

Figure 14. Predicted displacements for scenario southern Hayward fault earthquake. 


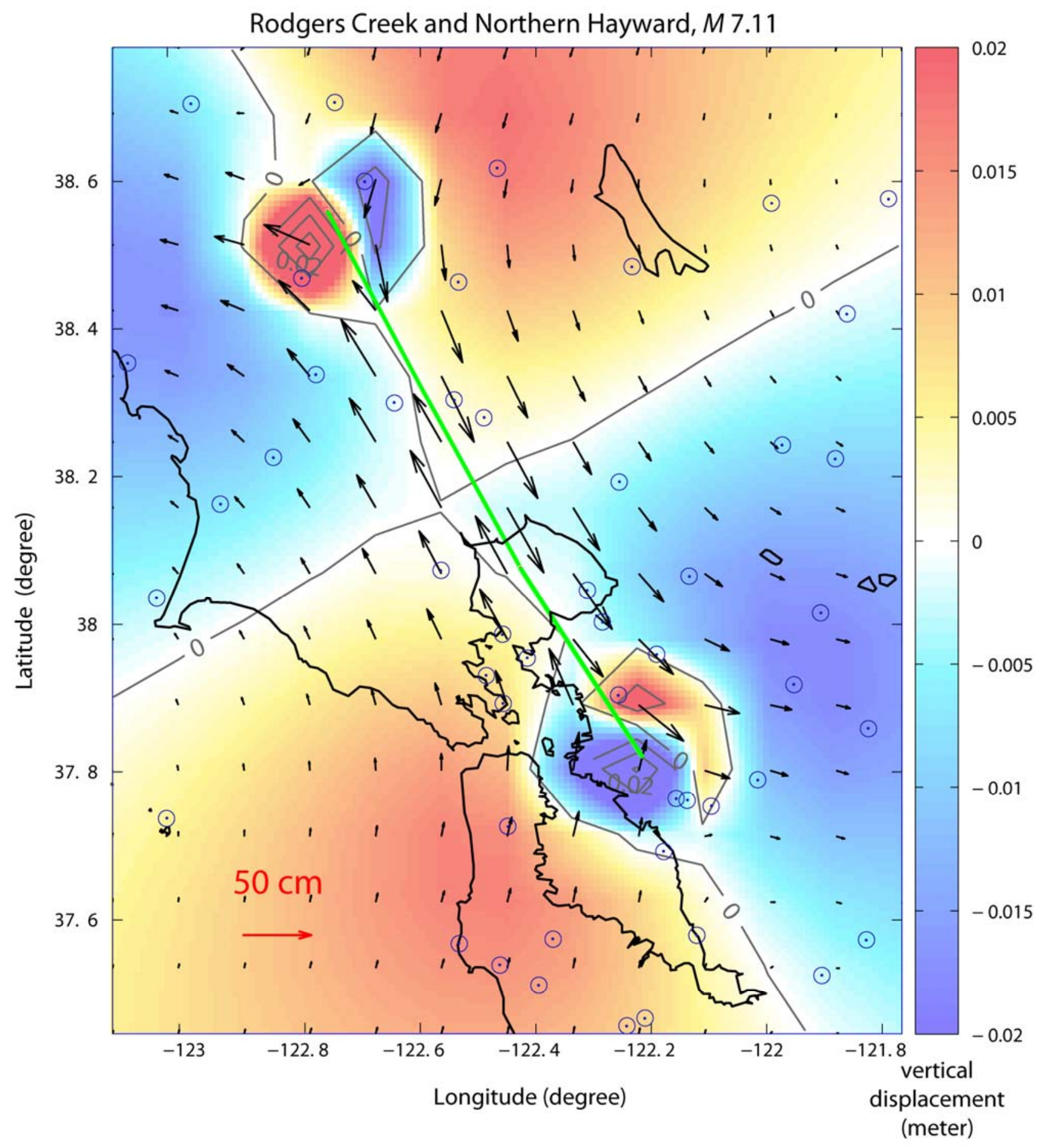

Contour interval: $2 \mathrm{~cm}$

Figure 15. Predicted displacements for scenario Rodgers Creek and northern Hayward fault earthquake. 


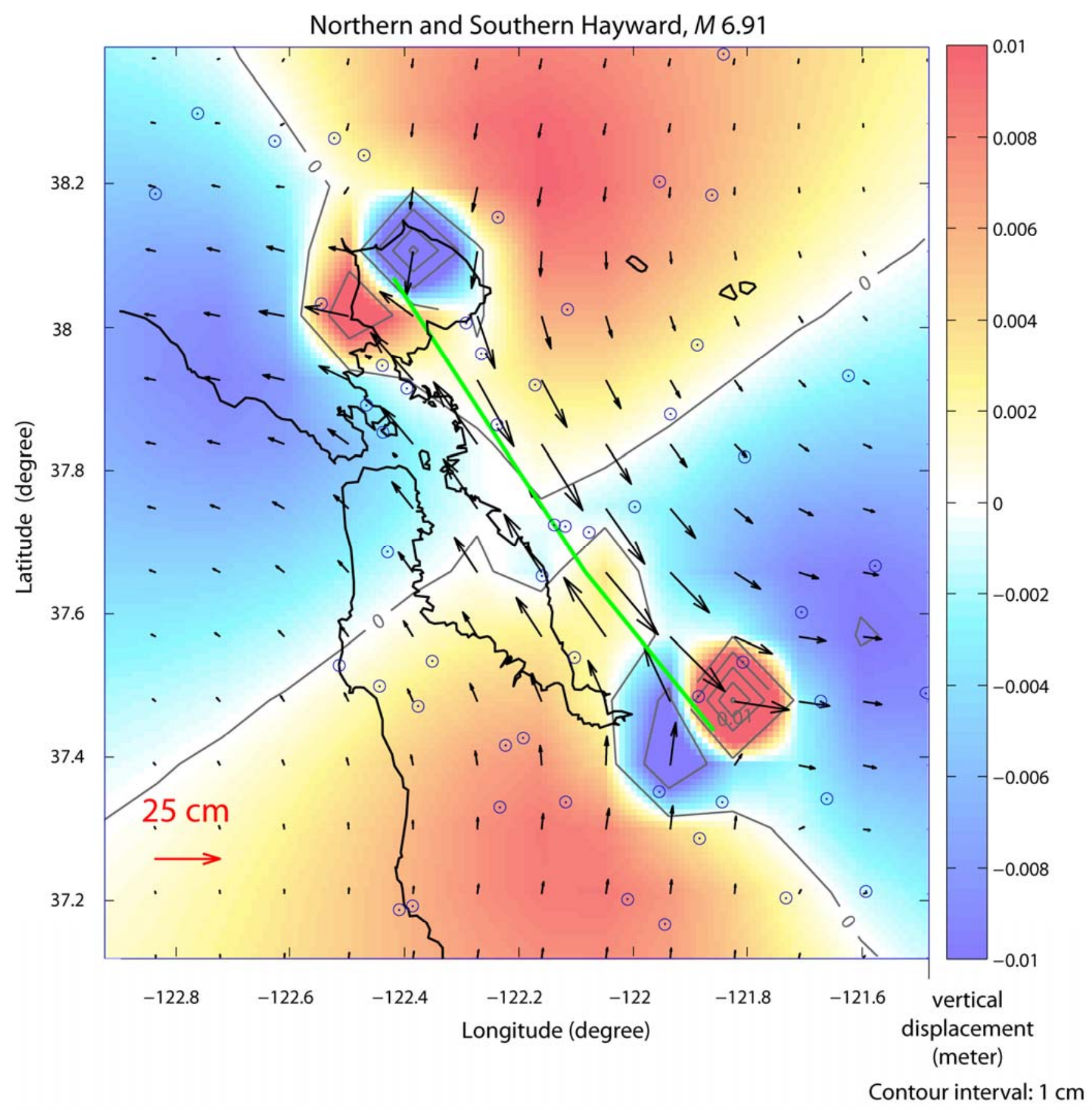

Figure 16. Predicted displacements for scenario northern and southern Hayward fault earthquake. 
Rodgers Creek, Northern and Southern Hayward, M 7.26

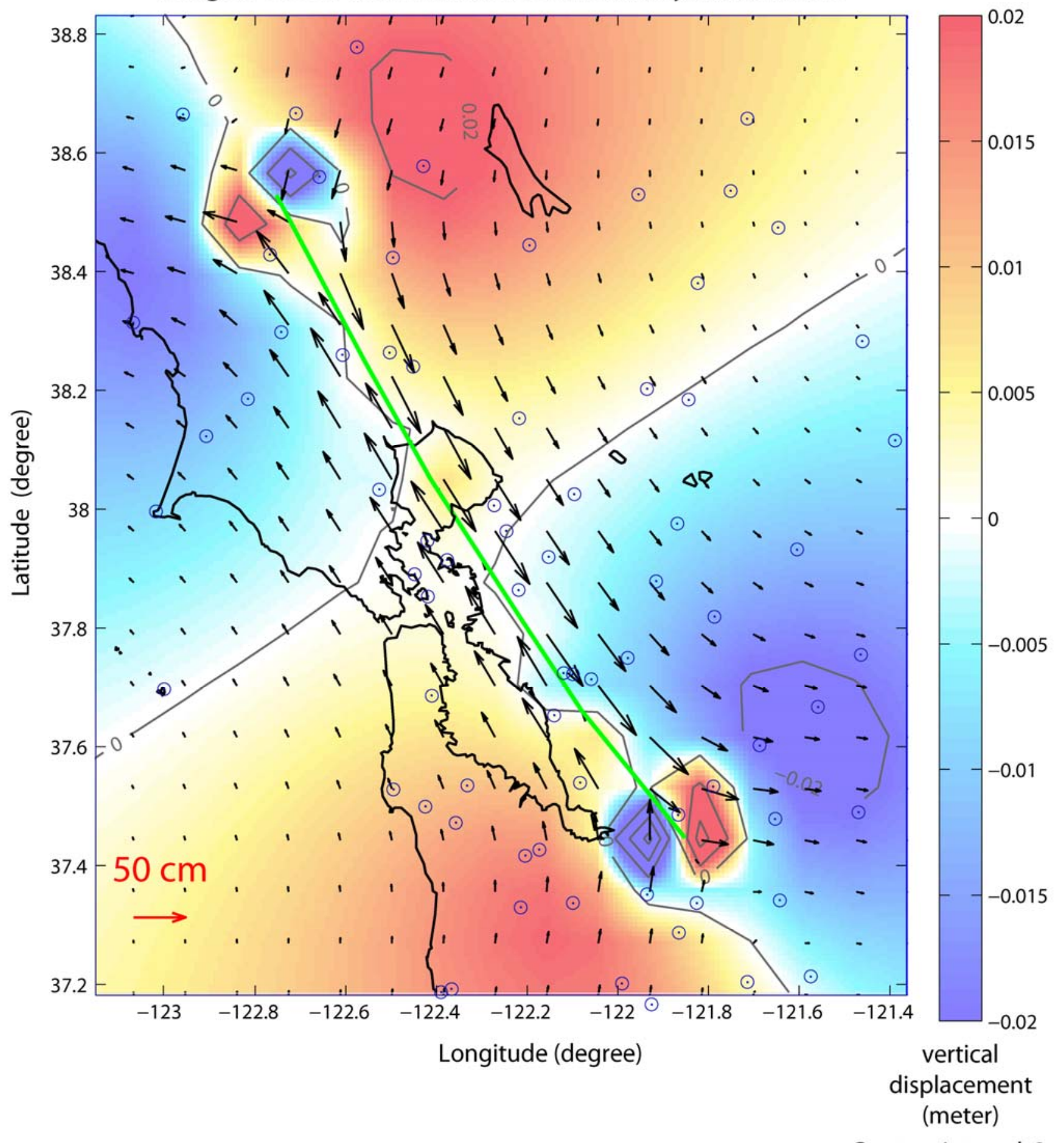

Contour interval: $2 \mathrm{~cm}$

Figure 17. Predicted displacements for scenario Rodgers Creek and northern and southern Hayward fault earthquake. 


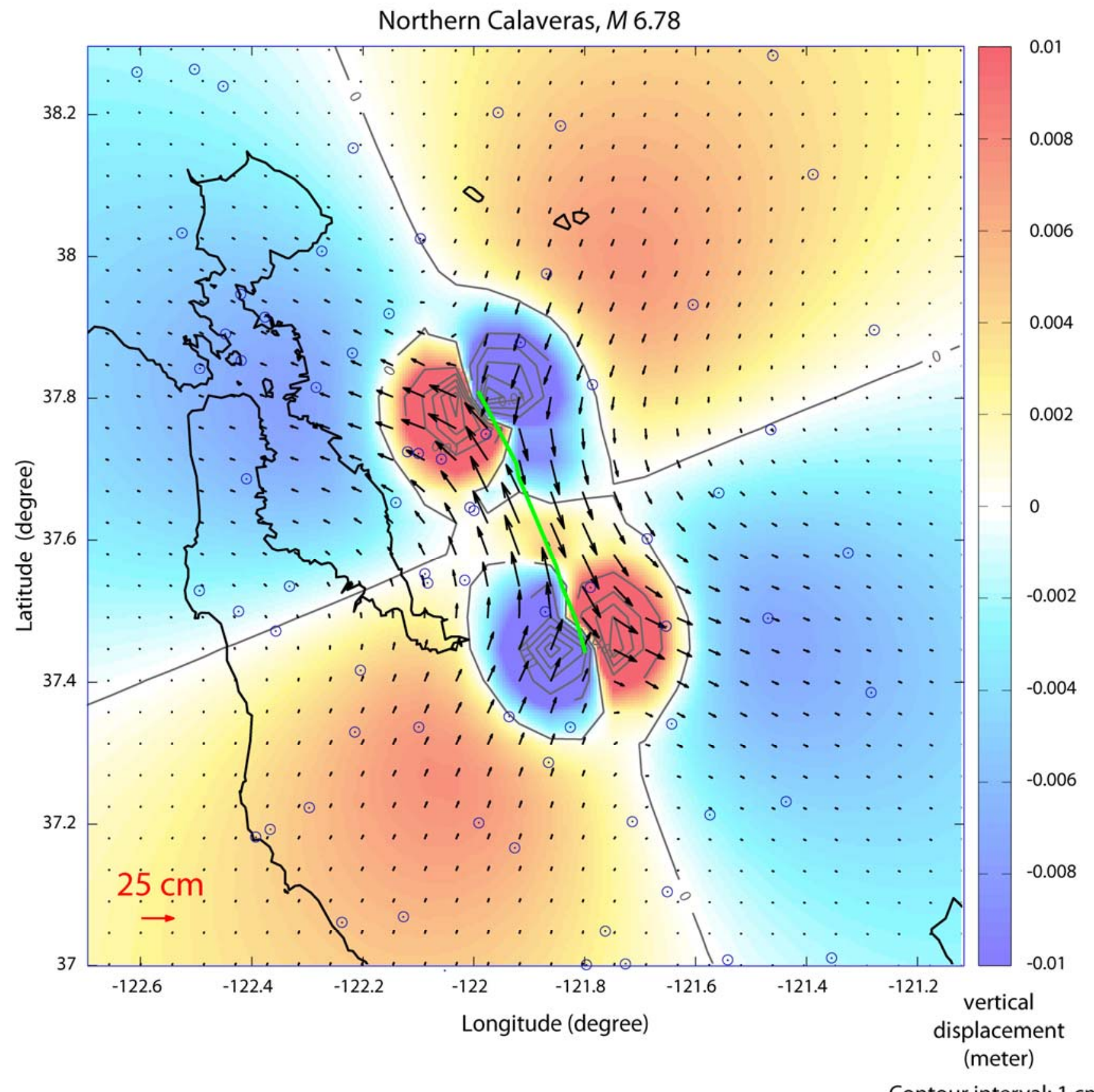

Contour interval: $1 \mathrm{~cm}$

Figure 18. Predicted displacements for scenario northern Calaveras fault earthquake. 


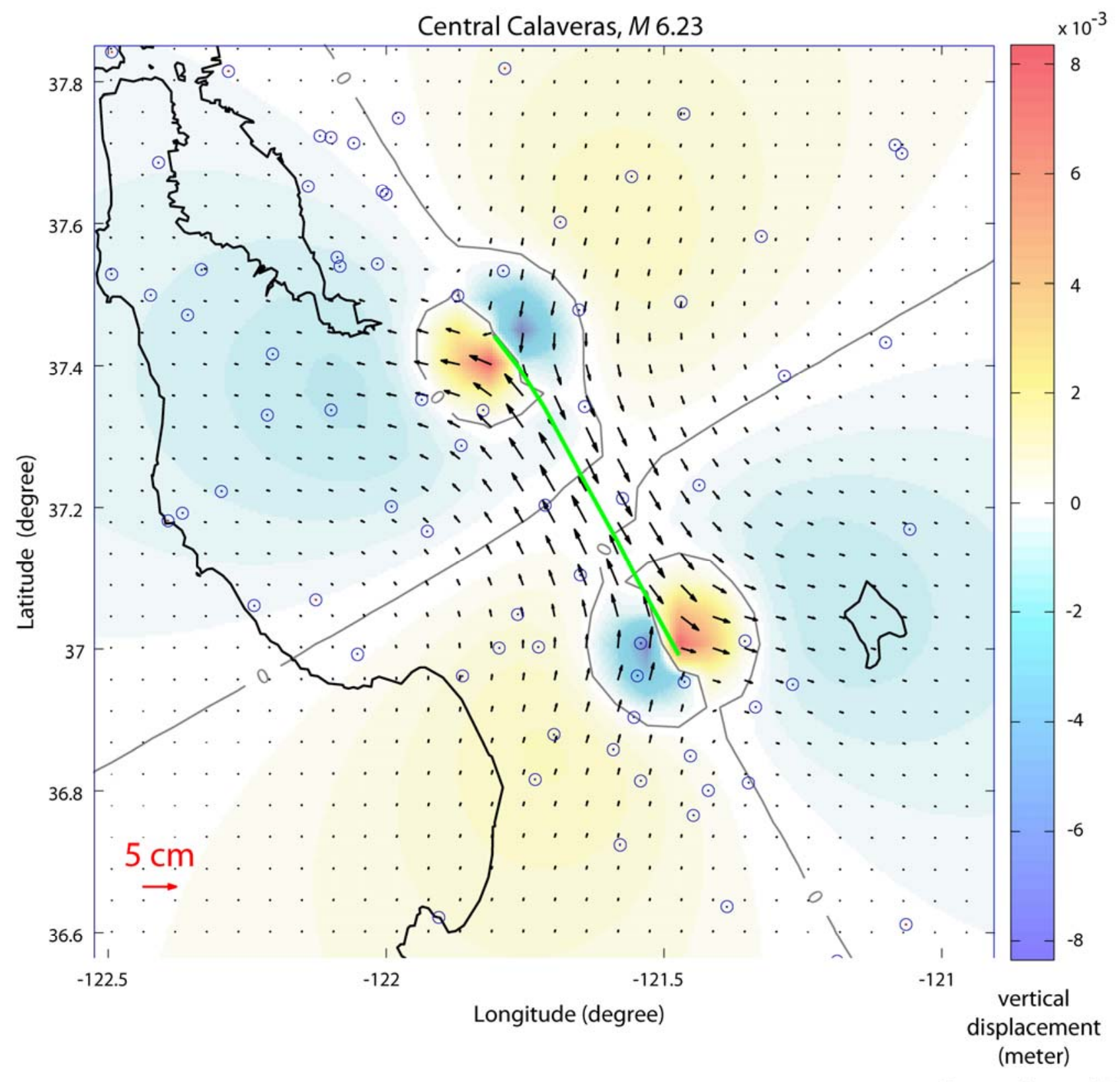

Contour interval: $1 \mathrm{~cm}$

Figure 19. Predicted displacements for scenario central Calaveras fault earthquake. 


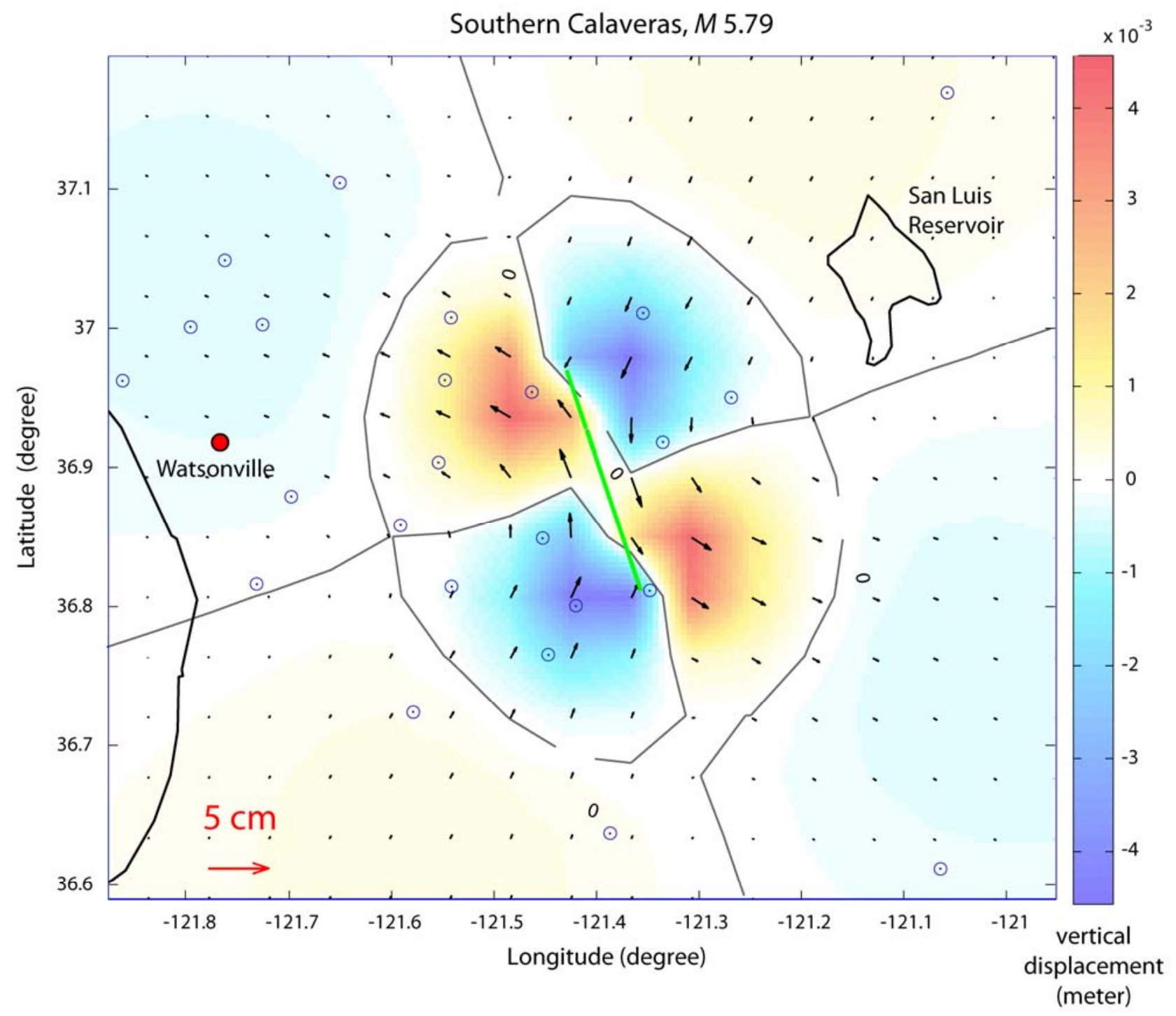

Contour interval: $1 \mathrm{~cm}$

Figure 20. Predicted displacements for scenario southern Calaveras fault earthquake. 


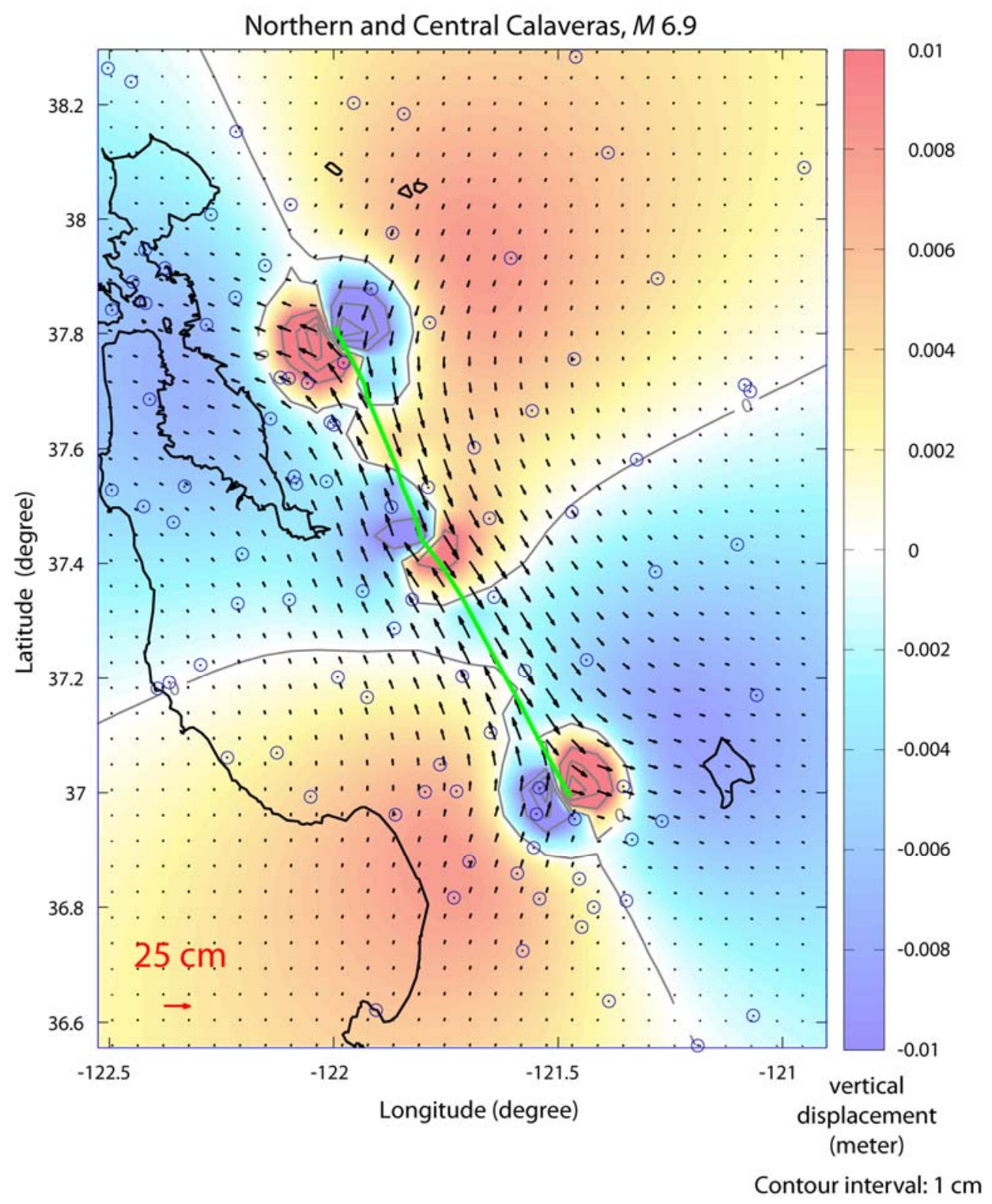

Figure 21. Predicted displacements for scenario northern and central Calaveras fault earthquake. 


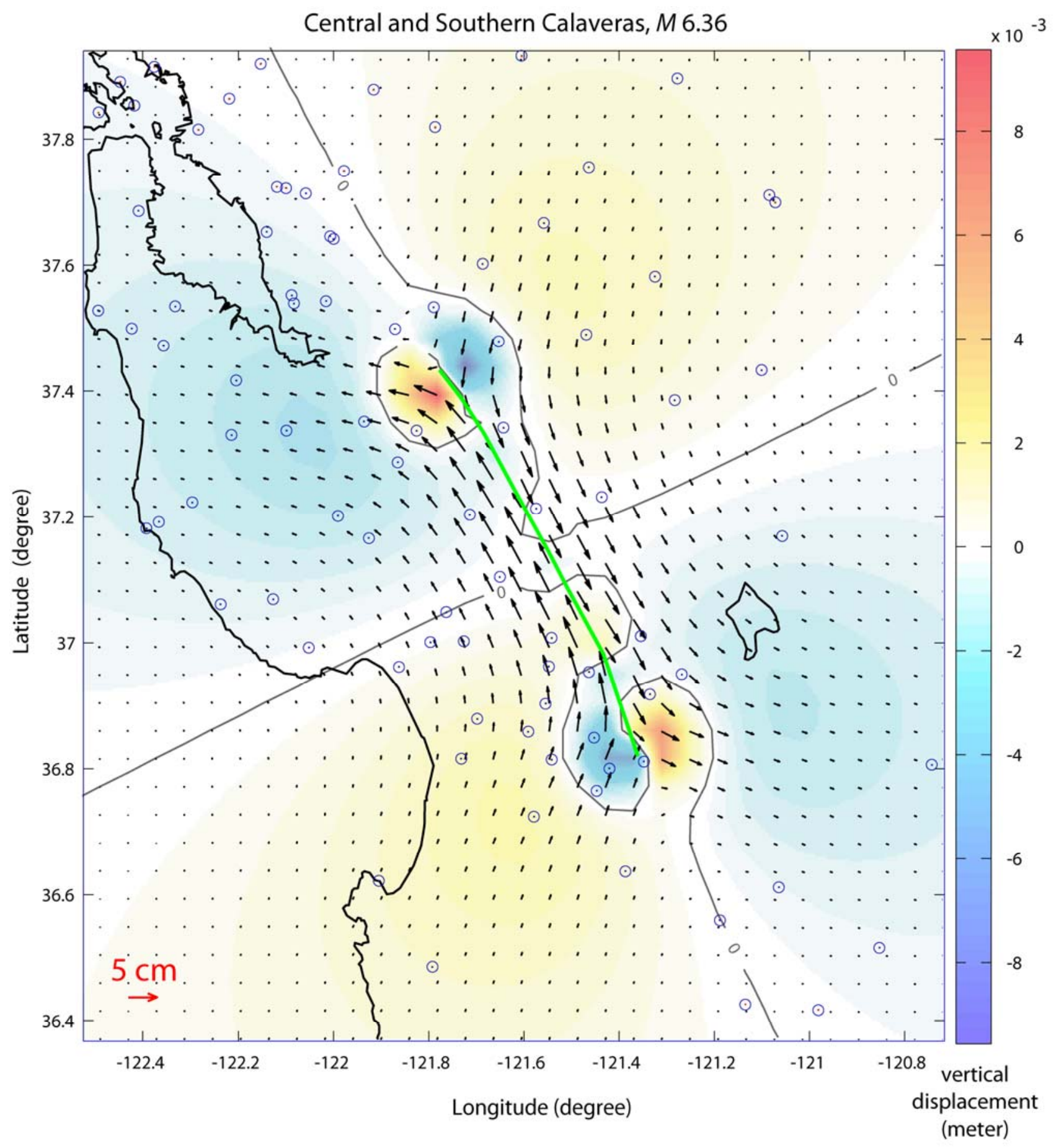

Contour interval: $1 \mathrm{~cm}$

Figure 22. Predicted displacements for scenario central and southern Calaveras fault earthquake. 


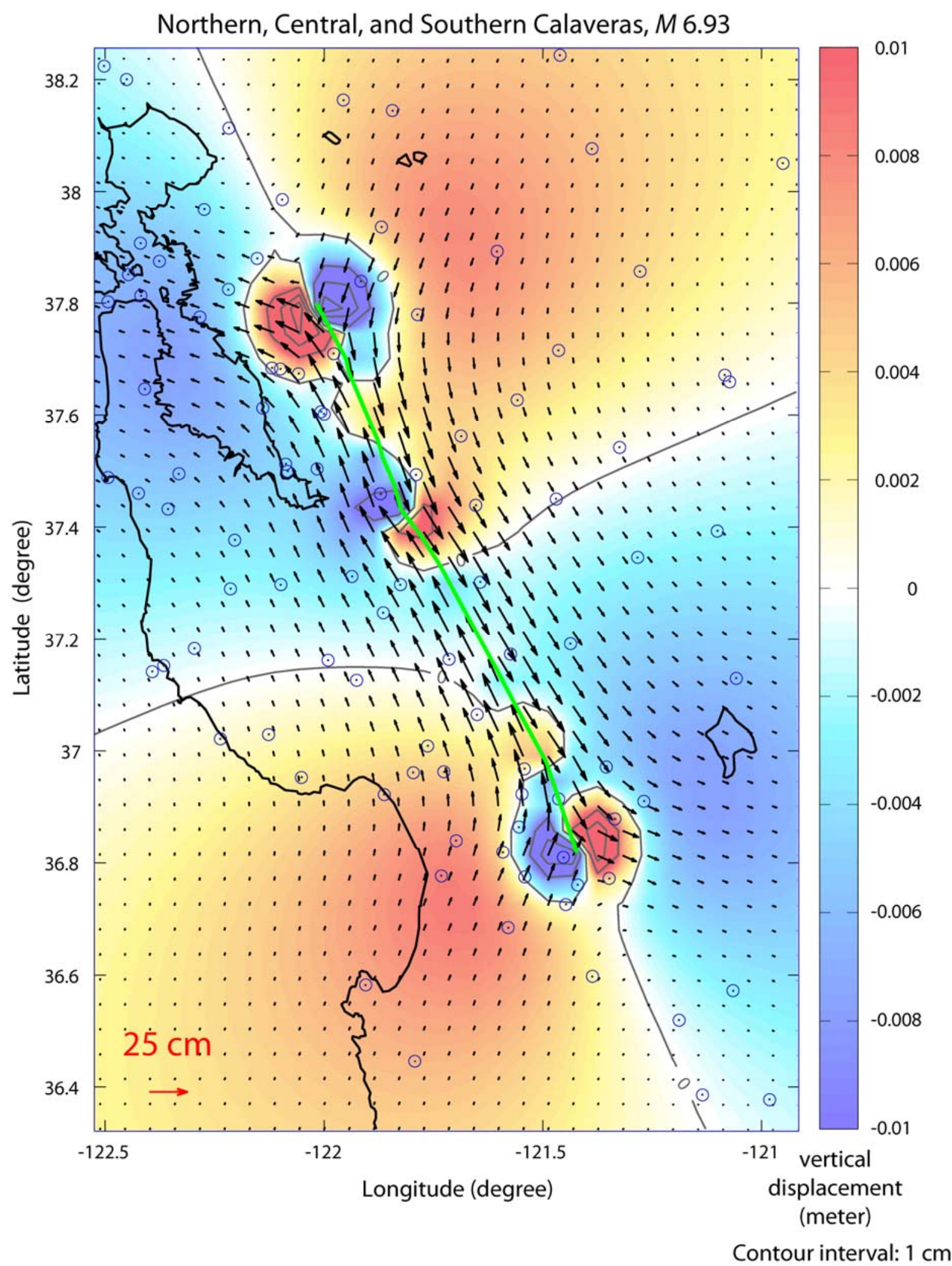

Figure 23. Predicted displacements for scenario northern, central, and southern Calaveras fault earthquake. 


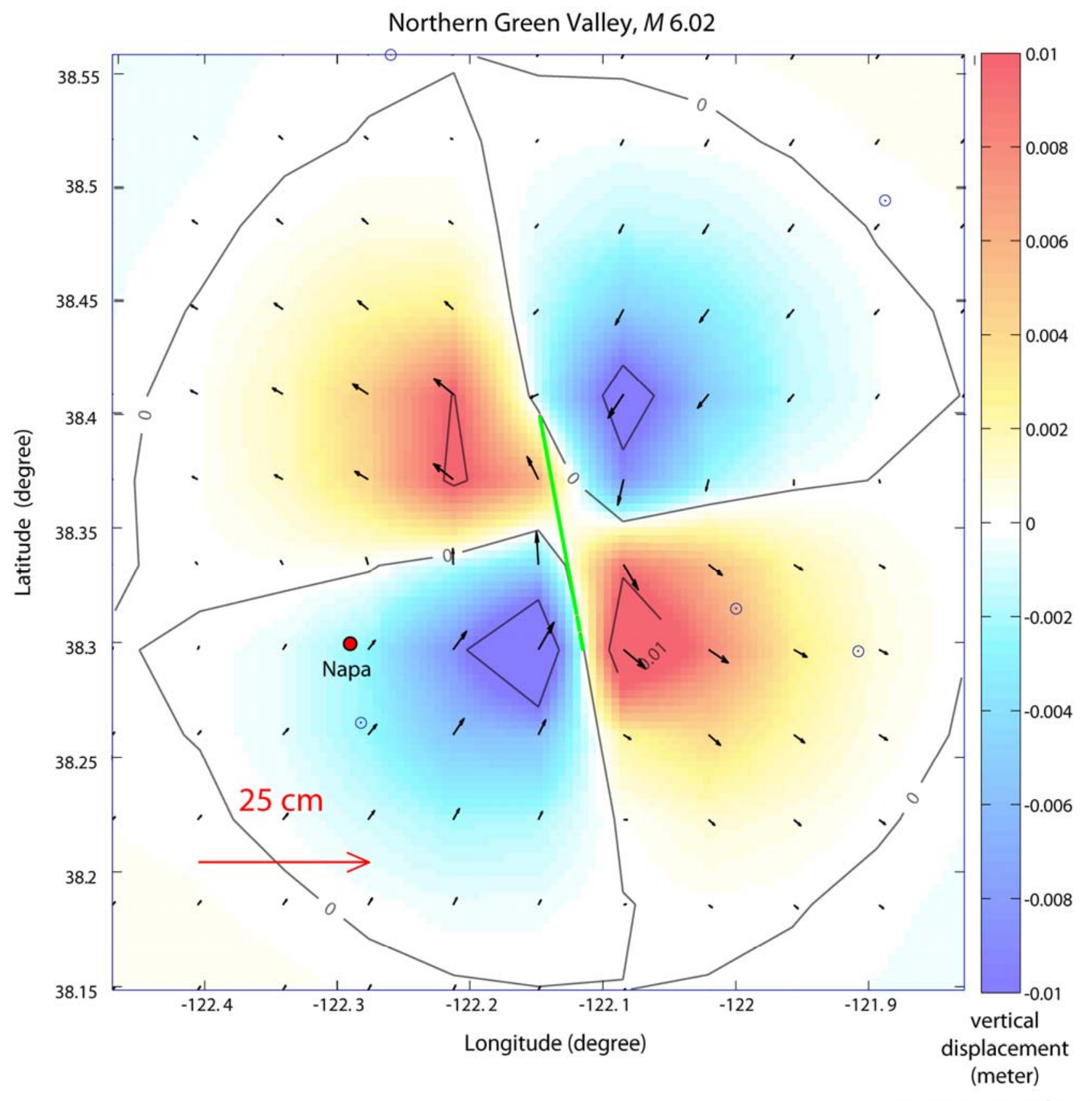

Contour interval: $1 \mathrm{~cm}$

Figure 24. Predicted displacements for scenario northern Green Valley fault earthquake. 


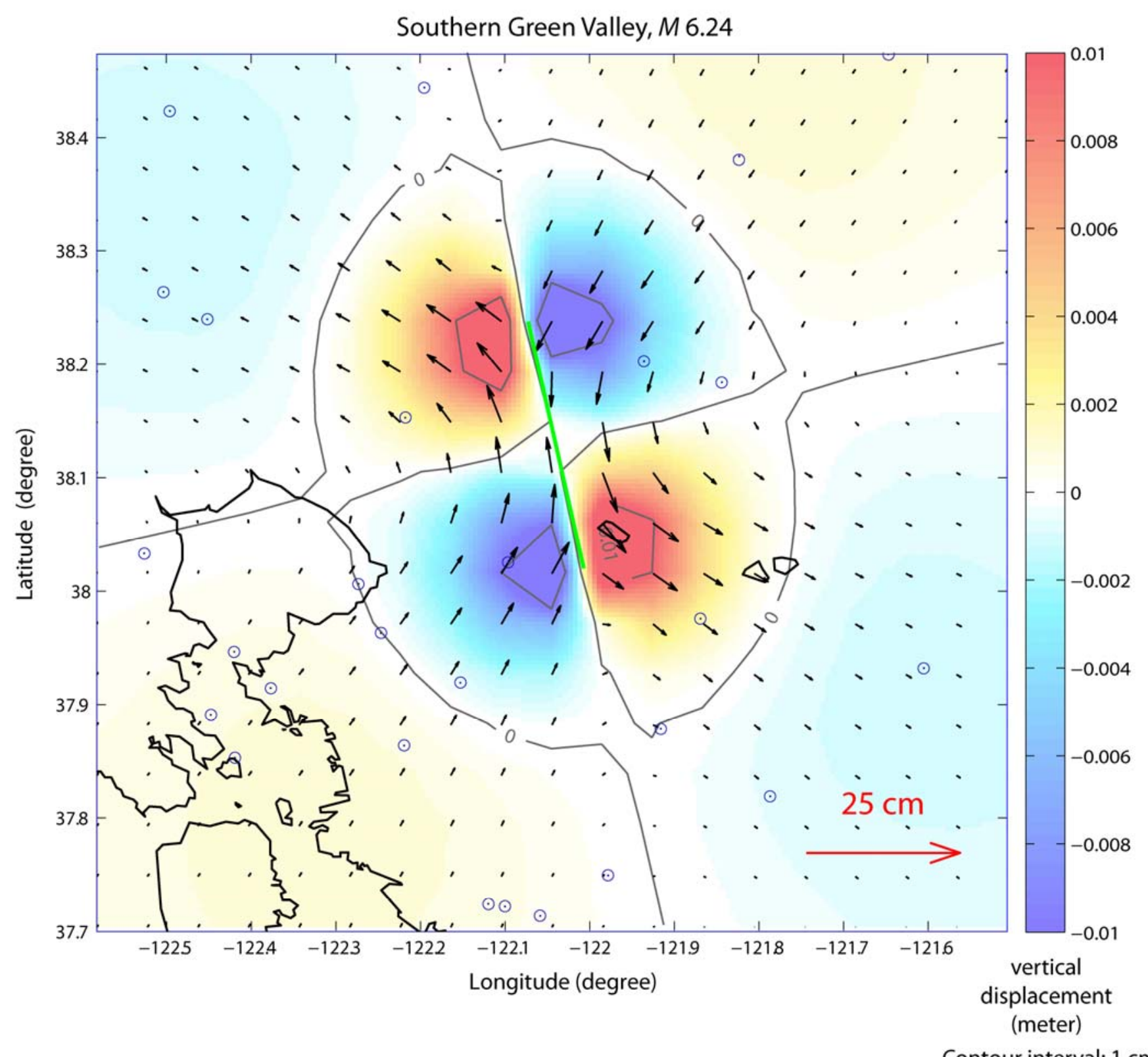

Figure 25. Predicted displacements for scenario southern Green Valley fault earthquake. 
Concord, M 6.25

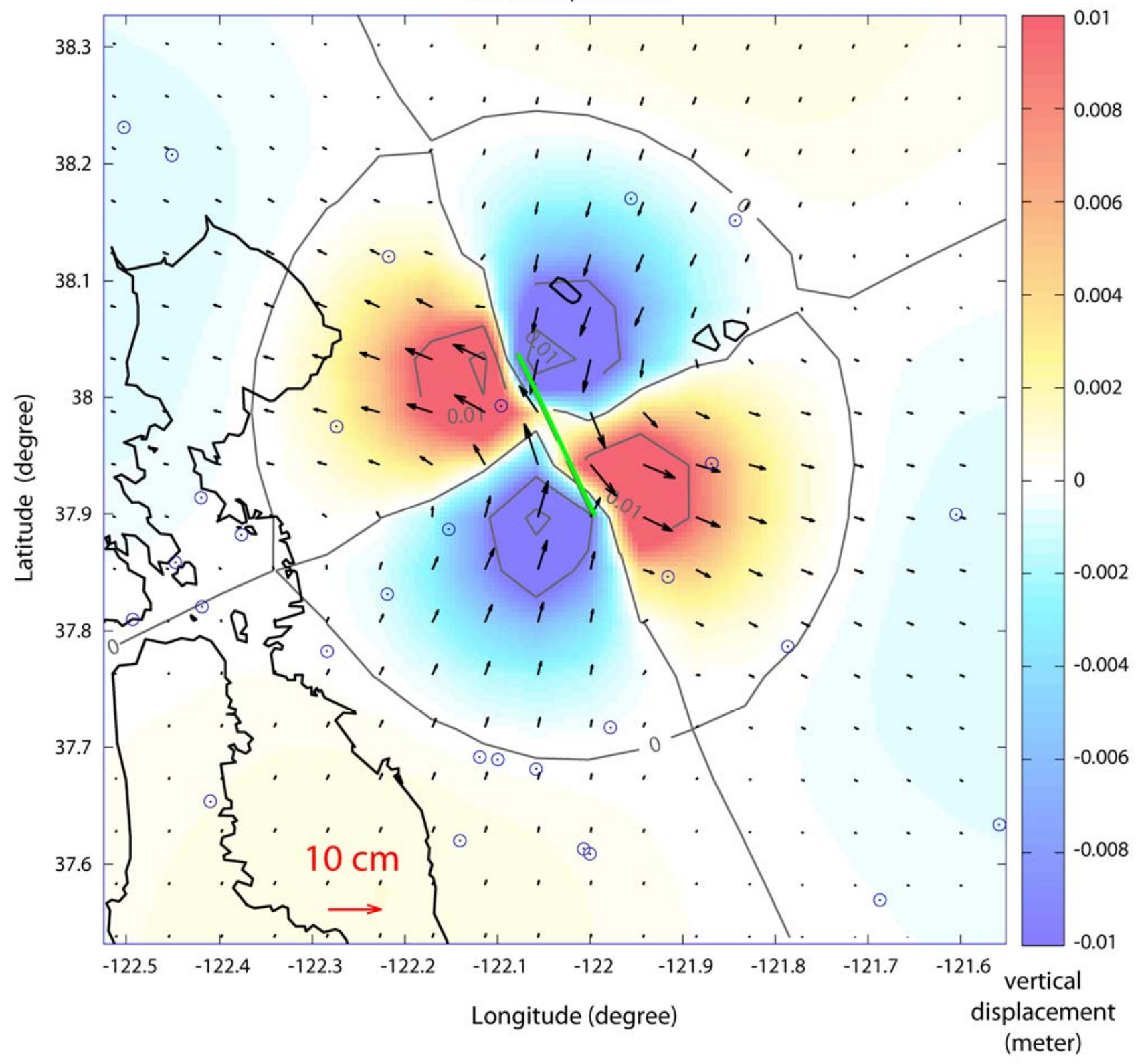

Contour interval: $1 \mathrm{~cm}$

Figure 26. Predicted displacements for scenario Concord fault earthquake. 


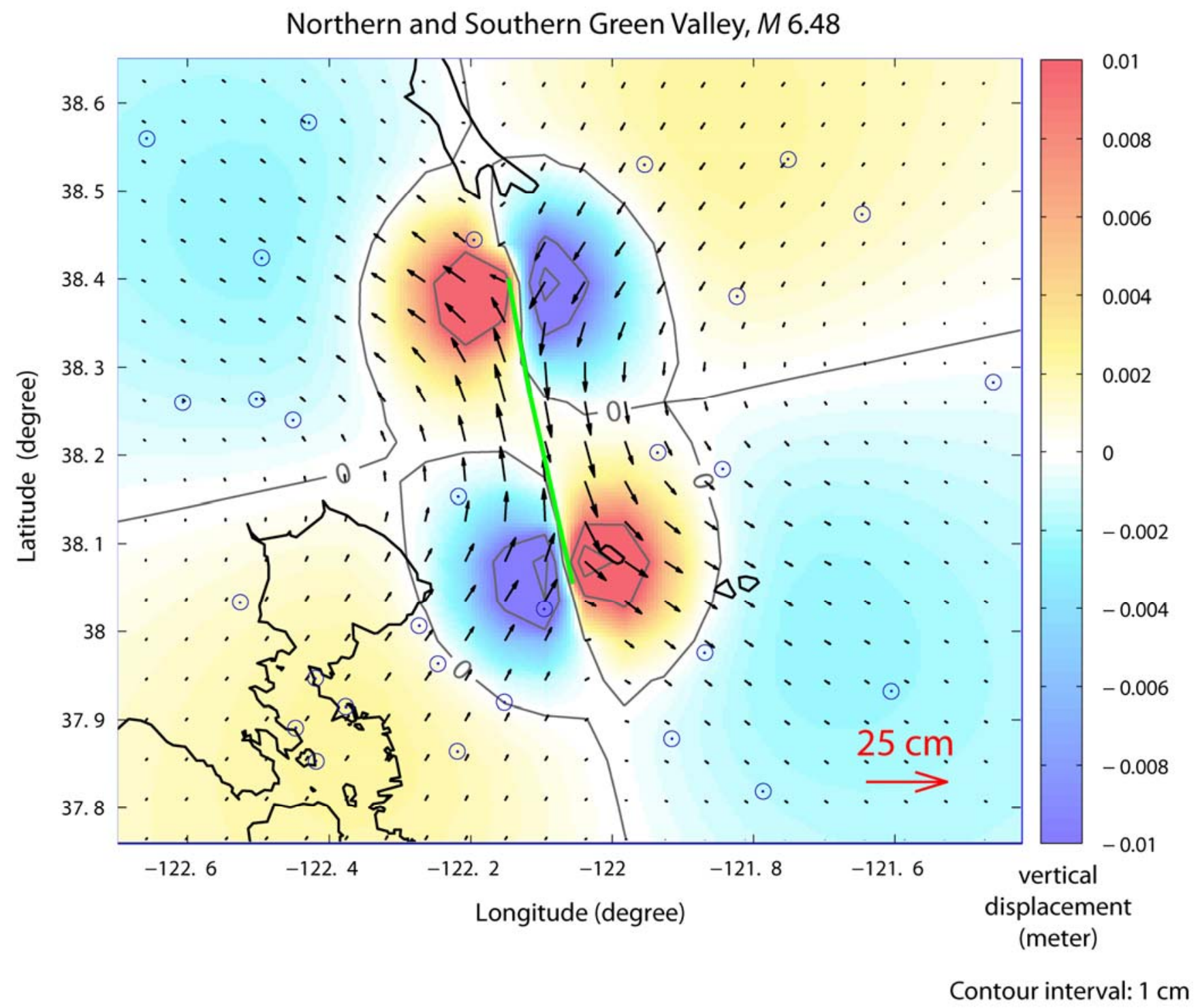

Figure 27. Predicted displacements for scenario northern and southern Green Valley fault earthquake. 


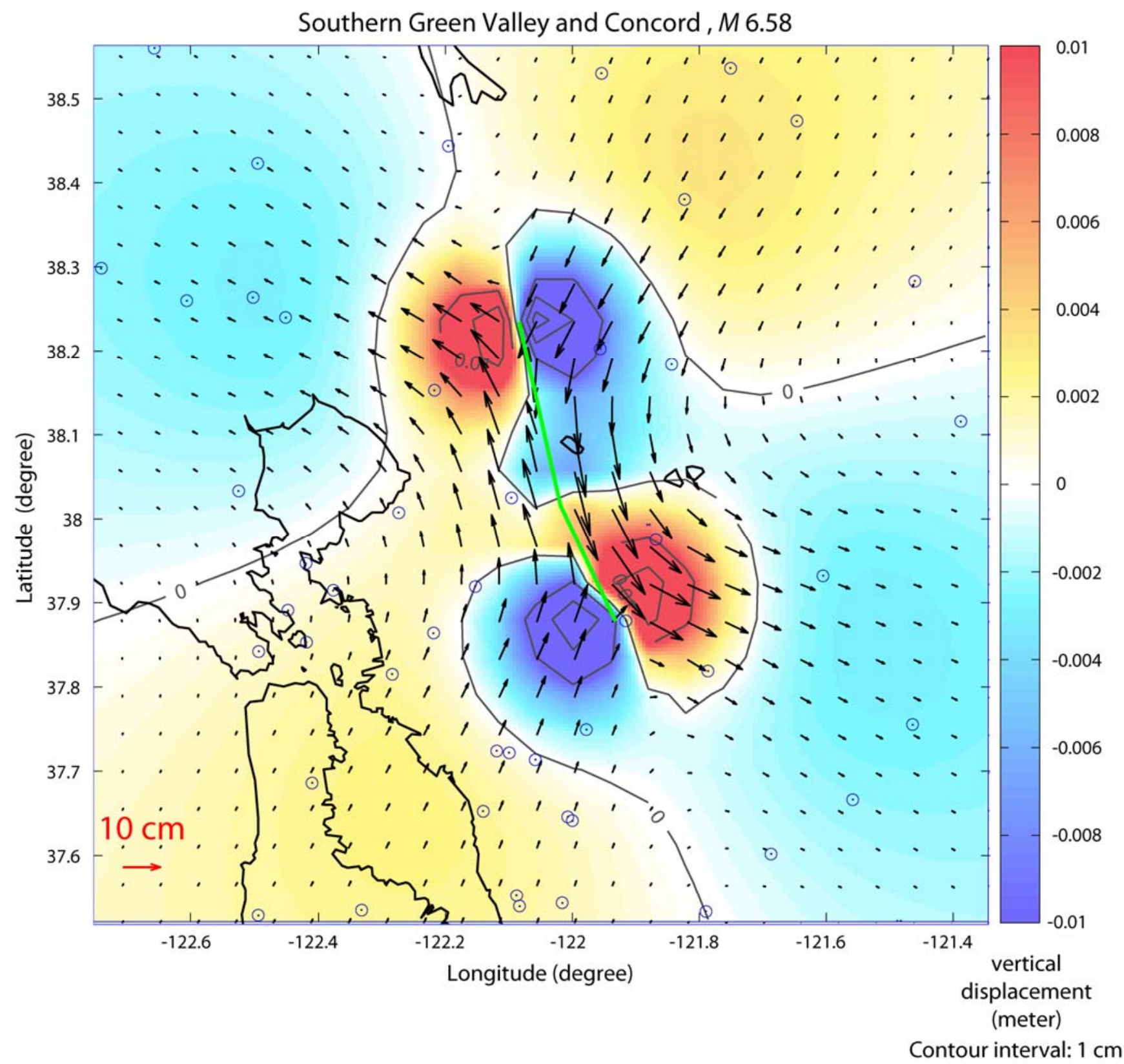

Figure 28. Predicted displacements for scenario southern Green Valley and Concord fault earthquake. 


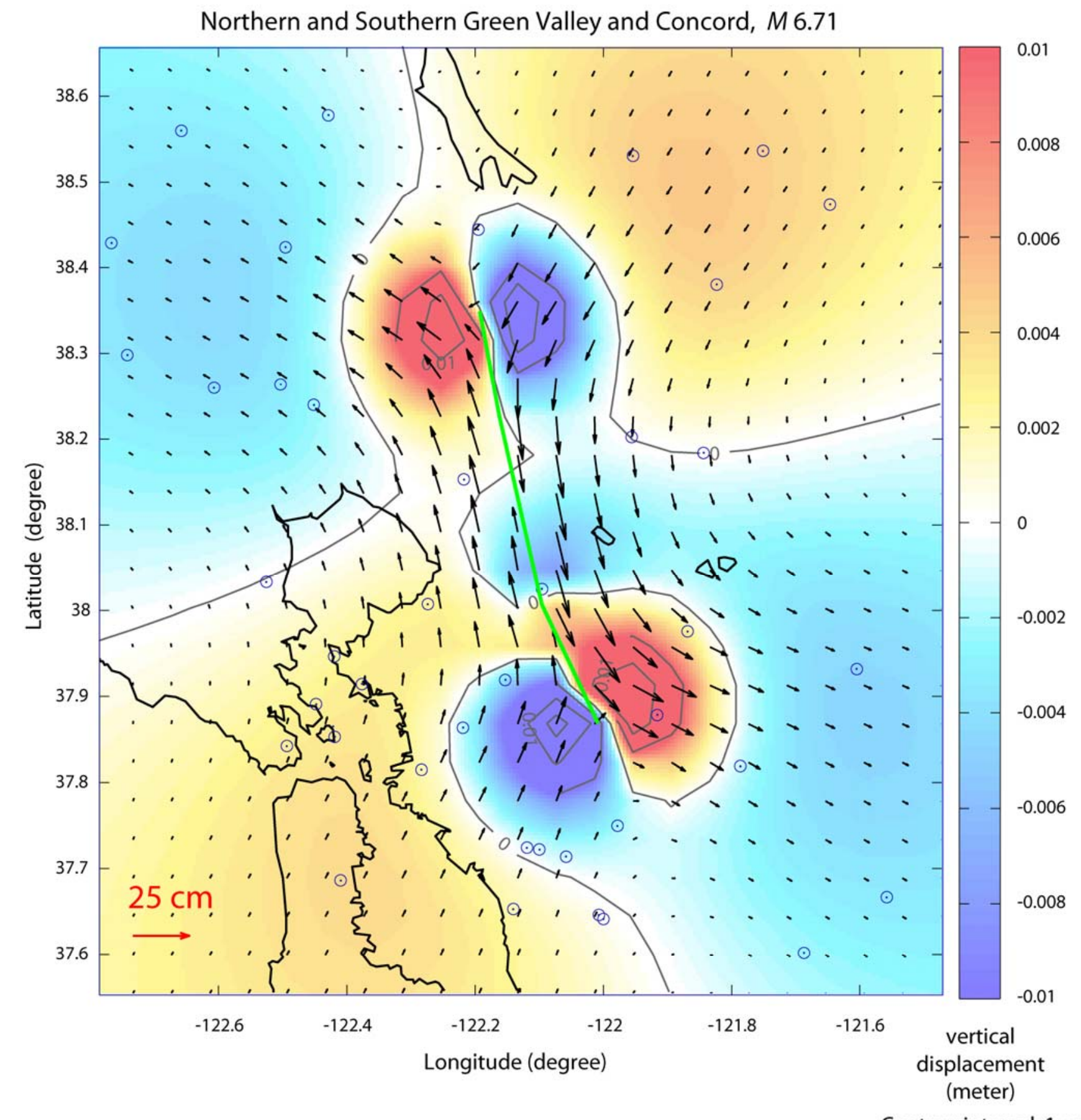

Contour interval: $1 \mathrm{~cm}$

Figure 29. Predicted displacements for scenario northern and southern Green Valley and Concord fault earthquake. 


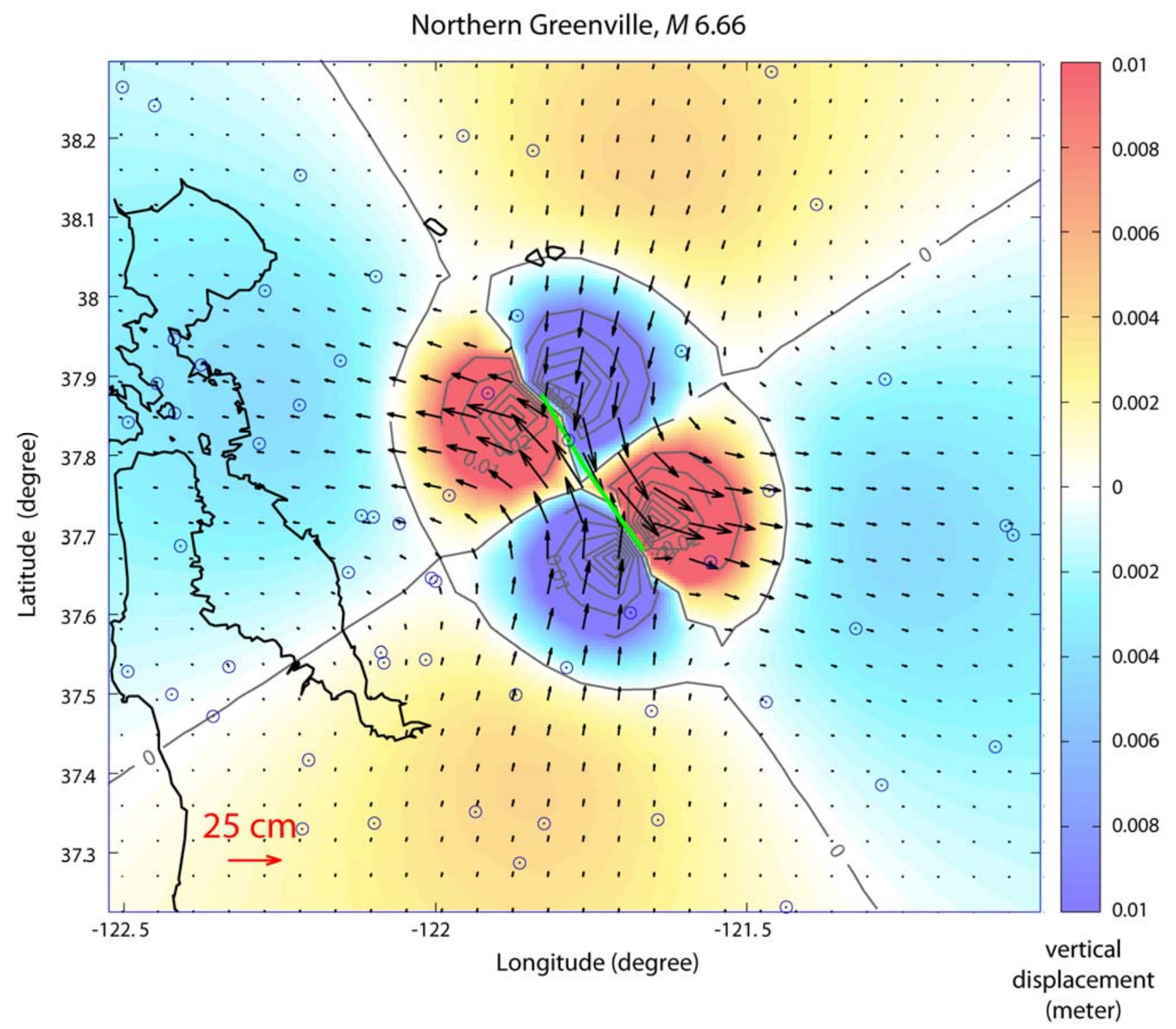

Contour interval: $1 \mathrm{~cm}$

Figure 30. Predicted displacements for scenario northern Greenville fault earthquake. 


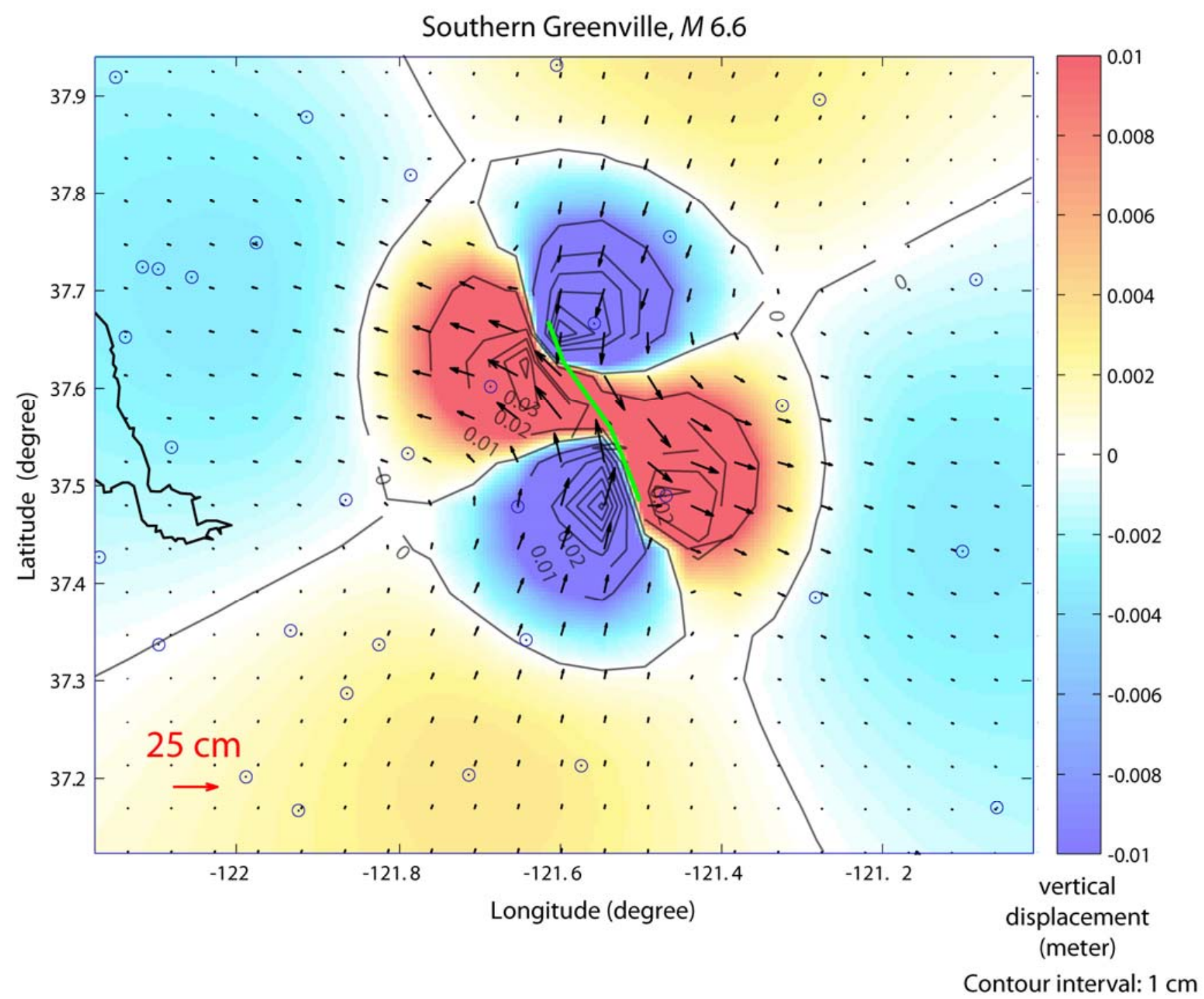

Figure 31. Predicted displacements for scenario southern Greenville fault earthquake. 


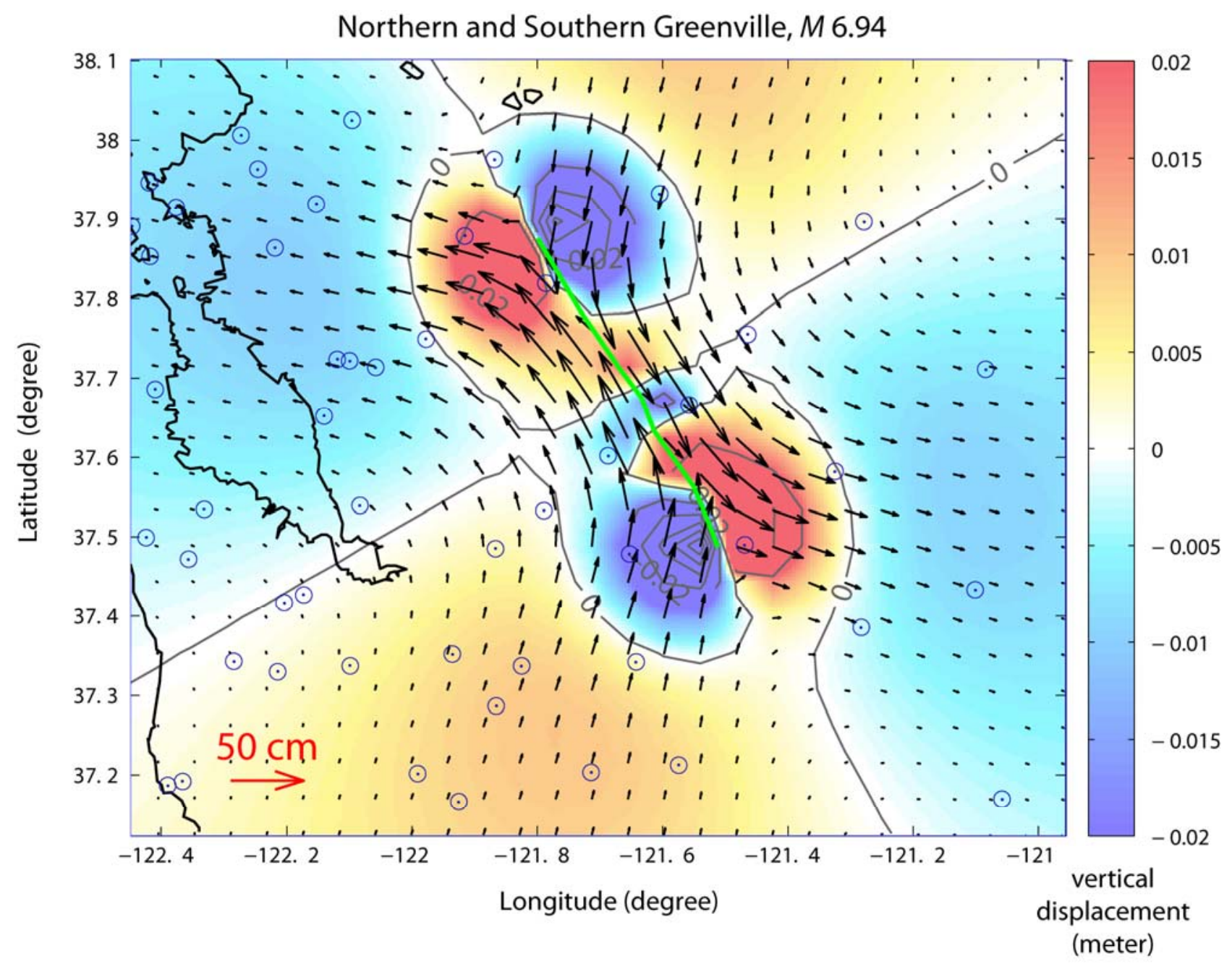

Contour interval: $2 \mathrm{~cm}$

Figure 32. Predicted displacements for scenario northern and southern Greenville fault earthquake. 


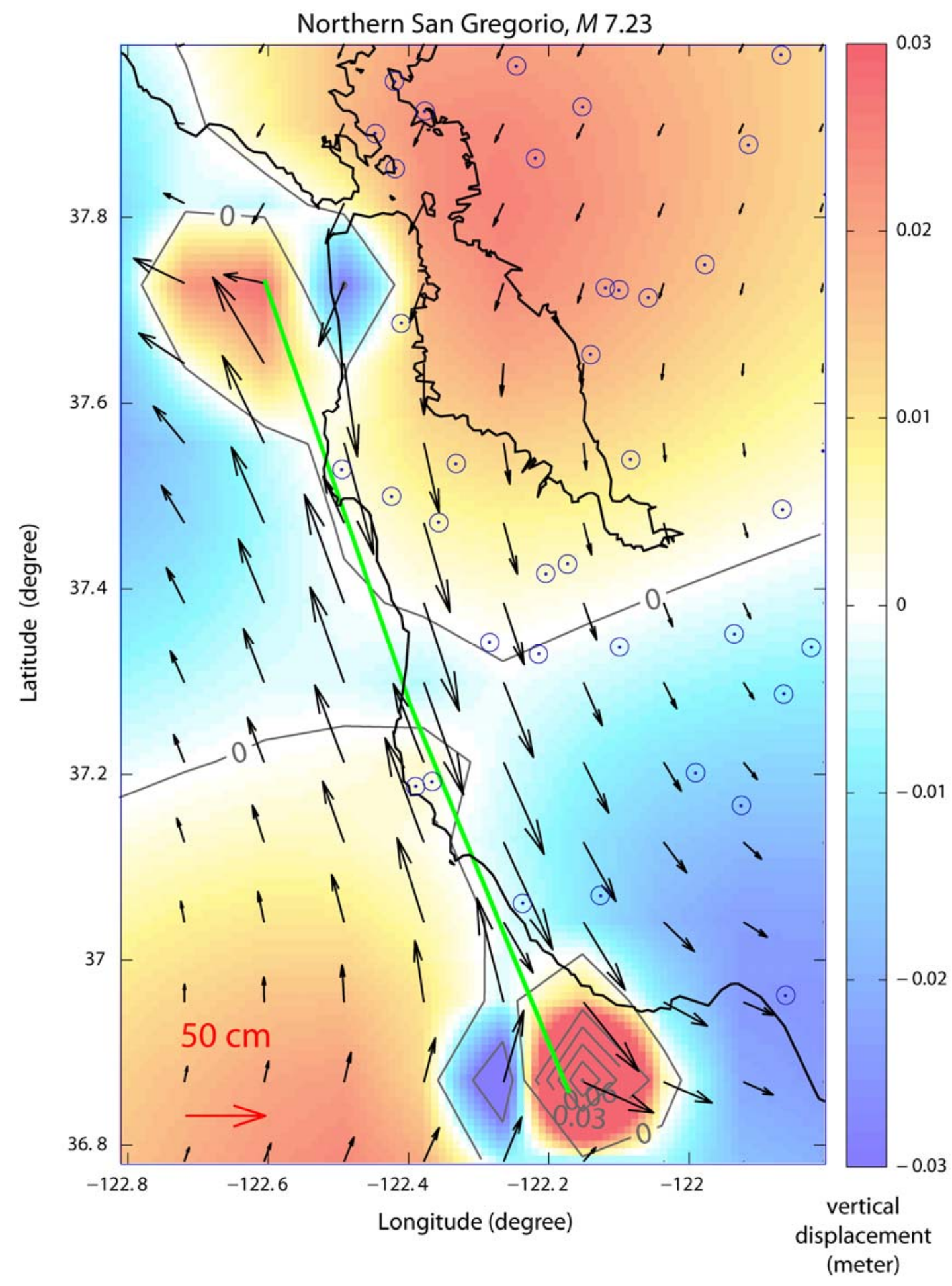

Contour interval: $3 \mathrm{~cm}$

Figure 33. Predicted displacements for scenario northern San Gregorio fault earthquake. 


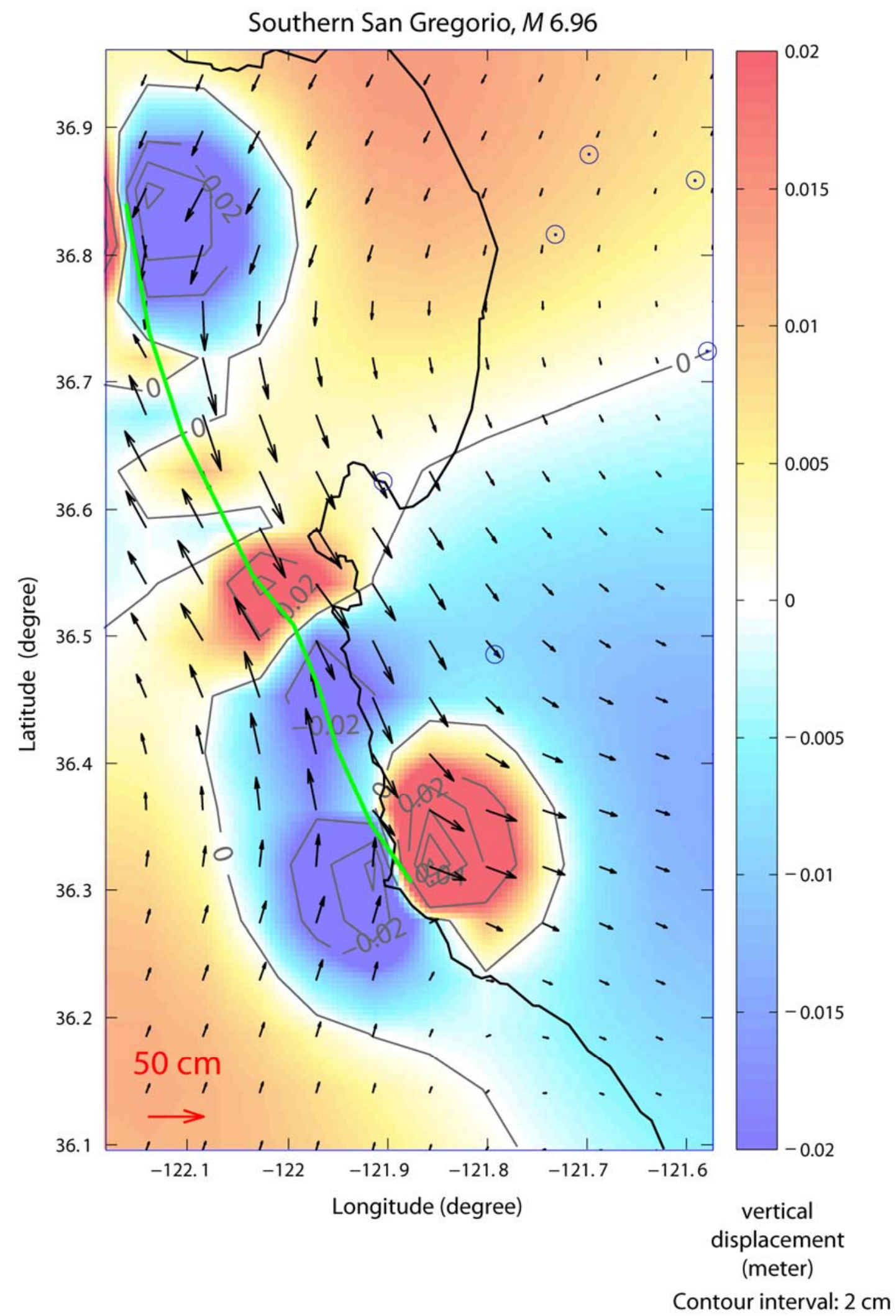

Figure 34. Predicted displacements for scenario southern San Gregorio fault earthquake. 


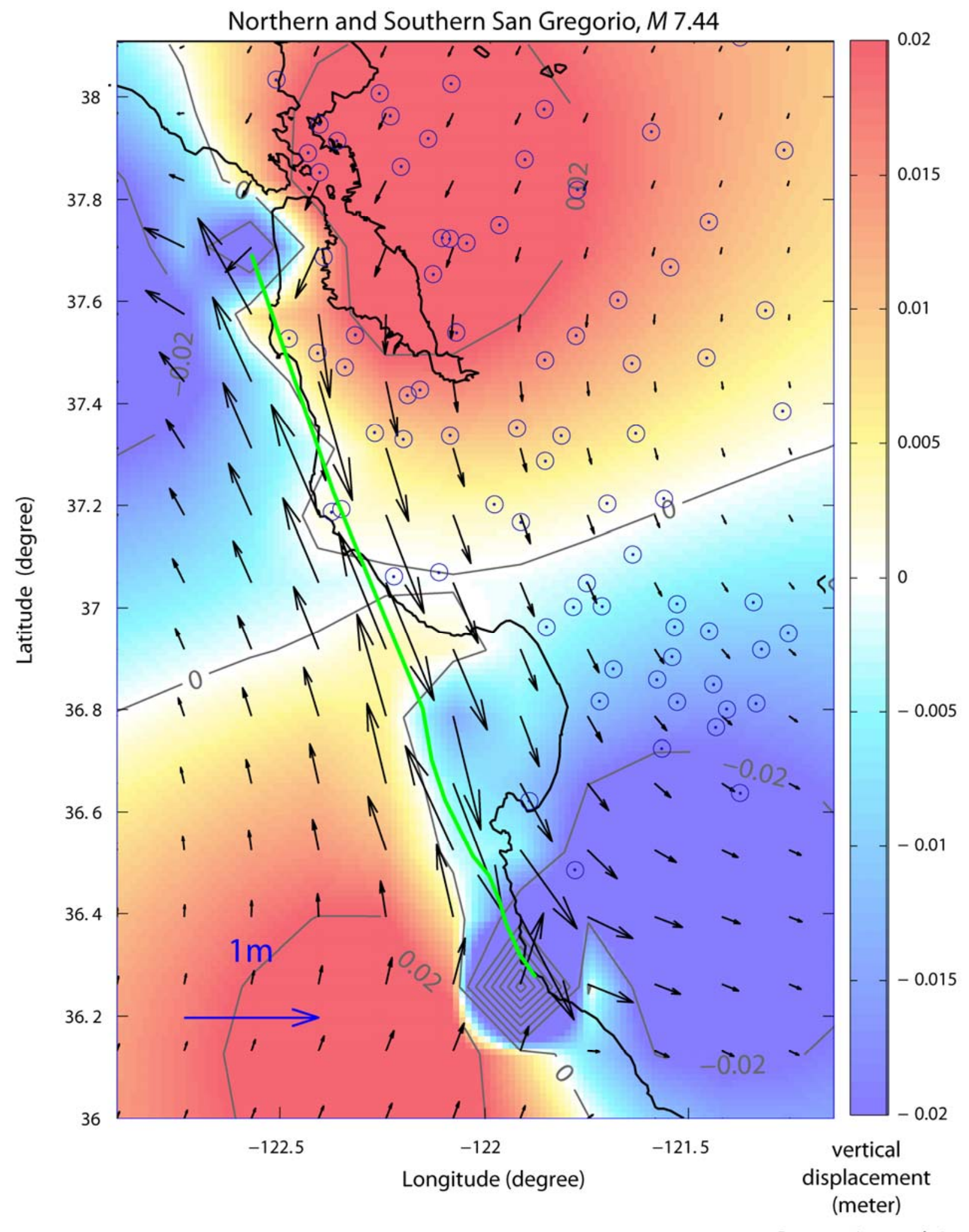

Contour interval: $2 \mathrm{~cm}$

Figure 35. Predicted displacements for scenario northern and southern San Gregorio fault earthquake. 


\section{Mount Diablo Thrust, M 6.65}

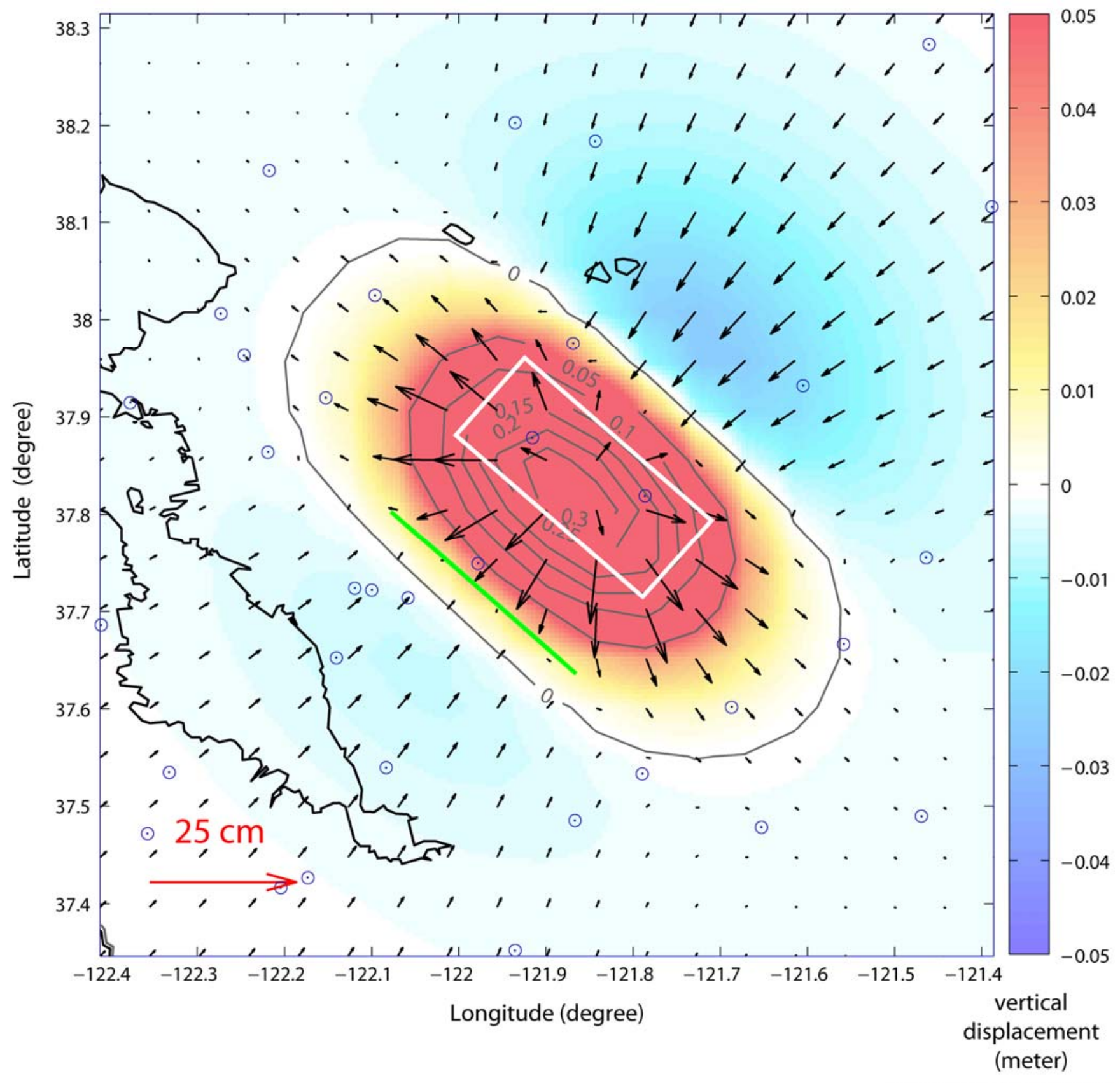

Contour interval: $5 \mathrm{~cm}$

Figure 36. Predicted displacements for scenario Mount Diablo thrust fault earthquake. 


\section{References Cited}

Lin, J., and Stein , R.S., 2004, Stress triggering in thrust and subduction earthquakes, and stress interaction between the southern San Andreas and nearby thrust and strike-slip faults: Journal of Geophysical Research, v. 109, B02303, doi:10.1029/2003JB002607.

Okada, Y., 1985, Surface deformation due to shear and tensile faults in a half-space: Bulletin of the Seismological Society of America, v. 75, p. 1135-1154.

Sleep, N., and Fujita, K., 1997, Principles of Geophysics: Blackwell Science, 586 p.

Toda, S., Stein, R.S., Richards-Dinger, K., and Bozkurt S., 2005, Forecasting the evolution of seismicity in southern California - Animations built on earthquake stress transfer: Journal of Geophysical Research, B05S16, doi:10.1029/2004JB003415.

Working Group on California Earthquake Probabilities, 2003, Earthquake probabilities in the San Francisco Bay region - 2002 to 2031: U.S. Geological Survey Open-File Rept. 03-214, 235 p. [http://pubs.usgs.gov/of/2003/of03-214/].

Working Group on California Earthquake Probabilities 2007, 2008, The Uniform California Earthquake Rupture Forecast, version 2 (UCERF 2): U.S. Geological Survey Open-File Rept. 2007-1437, 104 p. [http://pubs.usgs.gov/of/2007/1437/]. 